\title{
BULLETIN Bulletin hispanique
}

HISPANIQUE Université Michel de Montaigne Bordeaux

114-2 | 2012

Varia

\section{Mujeres}

un ramillete de tópicos amorosos en el teatro de Lope de Vega

\section{Antonio Ramajo Caño}

\section{(2) OpenEdition}

Journals

Edición electrónica

URL: https://journals.openedition.org/bulletinhispanique/1371

DOI: 10.4000/bulletinhispanique. 1371

ISSN: 1775-3821

Editor

Presses universitaires de Bordeaux

\section{Edición impresa}

Fecha de publicación: 31 diciembre 2012

Paginación: 561-596

ISBN: 978-2-86781-855-4

ISSN: 0007-4640

Referencia electrónica

Antonio Ramajo Caño, «Mujeres», Bulletin hispanique [En línea], 114-2 | 2012, Publicado el 05 enero 2016, consultado el 31 julio 2022. URL: http://journals.openedition.org/bulletinhispanique/1371 ; DOI: https://doi.org/10.4000/bulletinhispanique.1371

All rights reserved 


\title{
Mujeres: un ramillete de tópicos amorosos en el teatro de Lope de Vega
}

\author{
Antonio Ramajo Caño \\ Universidad de Salamanca
}

Nigra sum, sed formosa

Le pouvoir amoureux de la dame ressort avec éclat dans le théâtre de Lope de Vega. Le rôle féminin offre divers visages, de séduction ou de retenue. Les armes de la séduction sinscrivent dans des lieux communs dont l'histoire est ancienne. Certains d'entre eux font ici l'objet d'une étude, afin de mettre en relief la profonde culture du poète, en lien notamment avac la tradition classique.

Mots-clés : femme, séduction, retenue, lieux communs, tradition classique.

La fuerza amorosa de la mujer brilla en el teatro de Lope. La figura femenina ofrece diversas caras, de seducción o de contención. Sus armas atractivas lucen enmarcadas en tópicos de larga historia, algunos de los cuales se estudian en el presente trabajo, con el intento de insistir en la honda cultura del poeta, particularmente la relacionada con la tradición clásica.

Palabras claves: mujer, seducción, contención, tópicos, tradición clásica.

The amorous power of woman stands out in the plays of Lope de Vega. His female characters offer different aspects of the feminine, seductive or restrained. Their arsenal of attractions is framed in long time's commonplaces. The present study deals which some of them, in an attempt to assert the poet's deep cultural knowledge, particularly in relation to the classical tradition.

Key words: women, seduction, restraint, commonplaces, classical tradition.

T a pasión amorosa recorre los versos del teatro de Lope. Una lucha abierta L brota entre el desorden de los deseos y los cauces sociales. Parece como si el poeta, tan cristiano de alma, al menos en sus arrepentimientos hondos, se dejara llevar por un viento pagano y aceptara que el Amor domina a todos ( Omnia uincit 
Amon, Virgilio, Bucólicas, X, 69), incluso a los dioses, como Fedra recuerda al esquivo Hipólito, en Ovidio: "Regnat et in dominos ius habet ille deos» ${ }^{1}$. Con frecuencia, los personajes de Lope consiguen armonizar ambos polos. Destaca la inteligencia emocional de la mujer, que destinada a someterse a un amor por elección, consigue imponer el amor por destino ${ }^{2}$. No se doblegará ni siquiera ante las barreras físicas. Viajará con el amado o tras del amado. Para conseguir su objetivo, la mujer de Lope no dudará en disfrazarse (de otra mujer ${ }^{3} \mathrm{o}$ incluso de hombre ${ }^{4}$ ). Podrá incluso terminar en un hospital para locos, donde encontrará su verdadero amor (si el amor es locura, buen sitio tal microcosmos para tratar con él's). En el itinerario amoroso -que siguen los personajes de la comedia, en paralelismo con los enamorados de los cancioneros al modo petrarquista ${ }^{6}-$, los amantes, tanto varones como mujeres, tenderán a la monogamia ${ }^{7}$, pero no sin

1. Heroidas, IV, 12. Por la fuerza del Amor se intenta justificar incluso Adán. El Gigante corroborará: «Yerros, Adán, por amores, / dignos son de perdonar» (Lope de Vega, La puente del mundo, vv. 363-364, en Autos Sacramentales del Siglo de Oro, p. 124).

2. Y es que el verdadero amor es el provocado por el destino. Paris se esfuerza en seducir a Helena con la idea de que él está enamorado a causa del destino: «datum fatis... amorem» (Heroidas, XVI, 279). Vid. Petrarca: «[Amor] non per electïon, ma per destino» (CCXLVII, 14). Vid. Fernando de Herrera, Algunas obras, Sevilla, 1582: «Nací para inflamarme’ en la pureza / d'aquellas vivas luzes qu' al sagrado / cielo ilustran con rayos de belleza» (Elegía II, Poesía castellana original completa, p. 370). Vid. también F. de Herrera, soneto de hacia 1580: «Nací yo por ventura destinado / al amoroso fuego..." (Poesía castellana original completa, p. 328). Vid. incluso Don Quijote de la Mancha, I, cap. xiiii, palabras de Marcela: «El cielo aún hasta ahora no ha querido que yo ame por destino, y el pensar que tengo de amar por elección es escusado» (p. 155). Lope en su teatro distingue entre amor por elección y por accidente. Vid. Los amores de Albanio y Ismenia -1590-1595-: «Es Ismenia un altísimo sujeto / que obliga siempre a amar por accidente, / y cuando desta suerte no moviera, / la mejor elección del mundo fuera» (Jornada II, Comedias, II -no numeramos los versos, al no hacerlo los editores de la colección citada en las «Referencias bibliográficas»-, p. 604); vid. El caballero del milagro -1593-: «... el querer no es elección, / porque ha de ser accidente» (acto I, Comedias, I, p. 151); el criado Druso rechaza «el querer por elección, / que ha de ser por accidente» (Las Justas de Tebas y Reina de las Amazonas a. 1596, Jornada III, Comedias I, p. 794). En otras ocasiones la oposición se formaliza de manera léxica distinta: «Y todos dicen (...)/ que [el amor] nace de las estrellas» (El caballero de Olmedo, ¿1620-1625?, vv. 215-216, p. 115; cf. idéntica opinión en vv. 1724-1725, p. 174). En El palacio confuso, de 1624, la Reina elige marido, de acuerdo con las prerrogativas de las reinas sicilianas. Y elige a Carlos, aparentemente un plebeyo -en realidad, luego se demuestra que es noble-. La elección se basa en que «me arrebatan las estrellas» (dice la Reina: jornada I, 274, Lope deVega's El palacio confuso, p. 11; vid. también jornada III, 2343, p. 71); en otro lugar dirá: «me inclinó el cielo a tu amor, / que es Dios...» (jornada III, 3103-3104, Lope de Vega's El palacio confuso, p. 92; vid. también jornada I, 743, p. 24: «a los hados me rendí», ). Coincide en la obra el influjo de las estrellas con el gusto del pueblo, que es la voz de Dios, aunque parezca que es «monstruo sin razón ni auiso» (Jornada I, 731-732, Lope de Vega’s El palacio confuso, p. 24).

3. Doña María, en La moza del cántaro, de 1625-1627, se disfraza de Isabel, de inferior condición social.

4. Cf. Arjona (1937) y Teresa Ferrer Valls (2003).

5. Es el caso de Erifila en Los locos de Valencia, de 1590-1595, quien, por amor, había huido de su casa familiar con su criado Leonato. Pero, abandonada por éste, en el hospital, donde se finge loca, encuentra a Floriano, también loco fingido: y ambos acaban por casarse.

6. Vid. Ramajo (2002).

7. El auténtico amor conlleva la monogamia. Así responde Sirena al consejo de Venus de que 
perturbaciones y desconciertos, aunque, a la postre, con frecuencia, el yugo sacramental se imponga ${ }^{8}$. Y ese amor, encauzado en el camino matrimonial, no dejará de ser recio ${ }^{9}$, como que el autor se esfuerza por aliar libertad con sacramento, pasión con orden (las dos Venus ${ }^{10}$ ), con rechazo, insistimos, de la imposición autoritaria sobre los cónyuges ${ }^{11}$.

Este tipo desenvuelto de mujer, tan caro a Lope, no viene del teatro latino, en el cual la amada desempeńa un papel en extremo pasivo ${ }^{12}$, teatro en el que

ame a dos enamorados: «El amor ha de ser uno, / que esto bien los sabéis vos, / porque la que quiere a dos,/ no quiere bien a ninguno» (El Amor enamorado, de 1635, jornada III, vv. 22552258, p. 189).

8. Se dan, en efecto, los desconciertos transitorios de voluntades. Véase La moza de cántaro. «Amaba Filis a quien no la amaba, / y a quien la amaba, ingrata, aborrecía (...). / Seguía a quien, huyendo, la dejaba; / dejaba a quien, amando, la seguía (...)» (Jornada II, 1090-1094, p. 154). Estos desconciertos vienen, literariamente, de lejos: cf. Horacio: «Ipsum me melior cum peteret Venus, / grata detinuit compede Myrtale...» (I, xxxiii, 13-14: 'A mí mismo, cuando una Venus más apetecible me provocaba, me apresó la grata cadena de Mírtale'). Y como el matrimonio suele vencer, no faltan epitalamios en las comedias. Así, en El verdadero amante, ¿1585-1589?, un sacerdote ruega a Juno que sea propicia a los desposados: «iOh santa Juno (...), / asiste a nuestro deseo (...) / y venga en tu compañía / el sacro dios Himeneo» (acto I, Comedias, II, p. 89-90). Con todo, no siempre se impone el matrimonio. En el análisis de esta cuestión habría que realizar un «escrutinio más estrecho de las obras individuales», en expresión de Guimont y Pérez Magallón (1998: 164).

9. Ovidio nos ofrece el ejemplo de la casada llena de pasión. Laodamía, privada de su Protesilao, que ha partido a la guerra de Troya, confiesa que "pectora legitimus casta momordit amor» (Heroidas, XIII, 30). En el teatro de Lope se presenta una cierta ambigüedad en torno al amor matrimonial, ambigüedad que surge de lo que opinan diferentes personajes. Por un lado, parece que no puede ser auténtico el amor matrimonial, pues «que amor, puesto que es furor, I corre en casados templado" (El piadoso veneciano, 1599-1608, acto I, Comedias, XV, p. 490: así piensa Fulgencio); por otro lado, cuando el amor matrimonial existe, su intensidad sobrepasa la muerte: si una casada quiere a su marido «ni hay tiempo, muerte ni olvido, / porque es amor inmortal» (El piadoso veneciano, acto I, Comedias, XV, p. 490. así replica el criado Leoncio). En todo caso, las relaciones físicas son importantes en el matrimonio: "Cuando no hay quien se lo impida, / el que no goza no ama; / y un matrimonio sin cama / es como un cuerpo sin vida» ( $E l$ gallardo catalán, de 1599-1603, Jornada III: Comedias, XI, p. 181-182). Puede haber también ambigüedad en lo tocante al fundamento del amor. En El hidalgo Bencerraje, de 1599-1608, Fátima dice a su esposo Mahomad, rey y enamoradizo: «... Buen entendimiento, / porque éste es el fundamento / donde el amor siempre dura. / La hermosura el primer día / se goza, y siempre es menor (...). Lo que es nuevo en la mujer / siempre, para dar contento, / es el buen entendimiento» (acto I, Comedias, XV, p. 392); pero Mahomad piensa de manera distinta: «Amor entonces lo es / cuando anda todo al revés, / porque está su fortaleza / en ser el gusto cabeza / y ser razón los pies» (El hidalgo Bencerraje, acto I, Comedias, XV, p. 406).

10. Vid. Belardo el furioso, de 1586-1595: «... los dioses / por conservar la máquina del mundo, / pusieron un deseo en los mortales / que propagase (...) / su frágil y mortal caduco género; / dicen que éste es amor hijo de Venus, / no la que de la mar nació en la espuma, / sino la hija del purpúreo cielo, / que obliga con la fe del matrimonio» (Jornada II, Comedias, II, p. 505).

11. Florida, pastora, dice: «En no siendo el casamiento / con igual gusto y contento, / ninguno le ha de aceptar (...)» (La pastoral de Jacinto, de 1588-1598, acto III, 2747-2749, p. 169).

12. Caso distinto presenta el de la cortesana, a la que Lope se refiere cuando de su personaje llamado Dorotea dice: «discreta, pícara, grave, / decidora, limpia, vana, / cuanto en una cortesana 
el amor se presenta ya configurado, no en el itinerario amoroso del cortejo ${ }^{13}$ : de aquí que los tópicos amorosos del presente trabajo no se extraigan de las comedias latinas, sino de otro tipo de obras, de poesía, con frecuencia de carácter elegíaco. Acaso, en efecto, los antecedentes de los personajes femeninos de Lope haya que verlos en mujeres cargadas de furor, como la Dido de Virgilio o las protagonistas de las ovidianas Heroidas, sin descartar el modelo de arriesgadas enamoradas de novelas varias, caballerescas, bizantinas o pastoriles, o de alguna obra teatral prelopista -piénsese en la atrevida Lelia, de Los engañados de Lope de Rueda, que llega a disfrazarse de hombre, para estar junto al amado-. No podemos nosotros entrar aquí en cuestión tan delicada y de necesaria investigación. En todo caso, sí nos interesa resaltar que la mujer no ofrece una sola cara en los textos. Las habrá angelicales, que refrenan el corazón, parafraseando a Garcilaso, y las habrá que lo enciendan ${ }^{14}$. La mujer, insistimos, se presenta plural, para una relación de monogamia o en atracción poligámica; en pasión o en refrenamiento.

En las presentes páginas intentamos ofrecer un ramillete de matices eróticos que impregnan las tablas escénicas de nuestro gran autor áureo. Ese ramillete es, bien lo sabemos, una ínfima muestra de la riqueza que el Fénix nos regala. Sería preciso elaborar un diccionario de tópicos en el teatro de Lope. Ese diccionario sería lingüístico-literario, pues permitiría, en buena medida, recoger abundante léxico del escritor, pero no como un diccionario lexicográfico, sino contextualizando ciertas palabras en la semántica retórica del texto. Nuestras fuerzas proporcionan aquí una aportación modestísima, aunque el conjunto leído de comedias no sea pequeño, según se aprecia en el catálogo final del presente trabajo ${ }^{15}$. En nuestro estudio nos interesa, sobre

I de Plauto o Terencio cabe» (La prueba de los amigos, 1604, acto III, Comedias, XIII, p. 165). Pero esas palabras de Lope son más aplicables a Plauto que a Terencio (cf. Román Bravo 2001: 67-68). Es interesante la relación de personajes de comedia que presenta Ovidio: «Dum fallax seruus, durus pater, inproba lena / uiuent et meretrix blanda, Menandros erit» (Amores, I, xv, 1718. 'Mientras vivan el esclavo falaz, el padre rígido, la desvergonzada lena y la dulce cortesana, Menandro pervivirá). No figura en esa relación la joven a la que es preciso seducir. Según Grazia Profeti (2006: 210): «la comedia de los Siglos de Oro obedece de verdad a una manera nueva».

13. En las comedias de Plauto y Terencio, con frecuencia la joven no sale a escena (cf. Román Bravo 2001: 66, para Terencio). El cortejo puede, pues, estar ausente, aunque existe, al menos, la excepción del Poenulus de Plauto, acto I, escena II, en que sí se lanzan requiebros a la amada, pero, cómicamente, es el servus quien los profiere.

14. Ojea Fernández (2007: 81) habla de "pasión erótica» frente a «amor neoplatónico».

15. En ese diccionario habría que redactar entradas como la relativa al amor por fama, tan frecuente en Lope. Vid. lo que dice Hipólita en El príncipe inocente, de 1590: «Y así en la imaginación / un Alejandro he formado / a quien adoro y he dado / lo mejor del corazón» (acto I, Comedias, I, p. 64). Vid. El dómine Lucas, de 1590-1595: «... no hay en la corte dama / que no le quiera por fama, / y porque no tiene igual» (acto I, Comedias, III, p. 673). Vid. El leal criado, de 1594: «En esta edad lisonjera, / donde apenas hay verdad, / se engendra la voluntad, / de la fama novelera. / Ahora se entra el amor / a un hombre por los oídos...» (acto I, Comedias, I, p. 445). El tópico del amor por fama figura ya en Ovidio. Paris confiesa que se ha enamora de Helena antes de haberla visto: "Te prius optavi quam mihi nota fores; lante tuos animo vidi quam lumine vultus; / prima fuit vultus nuntia fama tui» (Heroidas, XVI, 36-38). Galmés de Fuentes (1996: 38-40) 
todo, marcar los lugares en los que florecen los diversos tópicos. Incluimos la cronología de cada comedia ${ }^{16}$, aunque, en nuestro entender, no se aprecian diferencias en la reelaboración de los tópicos de acuerdo con cambios en el tiempo en que la obra fue escrita, como no sea en el caso de la «mujer labradora», en el cual los ejemplos que aquí presentamos se estrechan cronológicamente, en una época de la madurez del Fénix. No es nuestro deseo ofrecer una investigación demorada sobre cada unos de ellos; no especulamos sobre el valor de cada tópico en la obra literaria en la que aparece, si tiene un simple carácter de exornación, de pulimento de la elocutio, o alcanza la categoría de elemento estructural configurador de las fuerzas semánticas del texto. Provisionalmente, nos inclinamos a pensar que los tópicos estudiados, salvo casos que se señalarán (como el citado personaje tópico de la «mujer labradora»), no superan ese primer nivel de embellecimiento del estilo. Pretendemos, con todo, de forma resumida, encauzar esos tópicos en la tradición literaria, en la creencia de que Lope posee un dominio bastante considerable del acervo legado por la literatura latina ${ }^{17}$,

y (2002: 412-423) considera que el tópico procede de la poesía árabe. Véase, además, Ynduráin (1983: 602-603). Vid. un útil muestrario de tópicos en Cañas Murillo (2003). Para el tópico del exclusus amator, cf. Ramajo (2004).

16. Para la cronología, tenemos presente lo que cada editor utilizado dice en su estudio, sin olvidar el trabajo fundamental de Morley y Bruerton (1968). Hemos procurado servirnos de buenas ediciones críticas, que señalamos. Pero, con frecuencia, nos vemos obligados a leer la colección de la Biblioteca Castro, que, con todo, parece ofrecer un texto fiable. Es de justicia anotar las buenas ediciones que de las Comedias de Lope de Vega se están publicando bajo la dirección de Alberto Blecua y Guillermo Serés, Barcelona, Universidad Autónoma.

17. Para la formación clásica de Lope, acaso sea interesante reproducir, aunque sea largo, el diálogo entre Feduardo, hijo natural del Duque de Milán, buen humanista, y su criado Gonzalo, al llegar a Roma, en El secretario de sí mismo, de 1604-1606, en el que se nos proporciona un canon parcial de la literatura latina: «FEDUARDO: Estos despojos / de la romana grandeza: / baños, termas y teatros, / colosos, anfiteatros, / reliquias de aquella alteza. / Lo que en César he leído, en Salustio, en Cicerón, / en Livio, que historias son / de lo que este imperio ha sido, / traigo a la memoria ahora. / ¡Oh, quién a Virgilio viera, / y mil abrazos le diera! / Tanto mi ingenio le adora. / (...) Con qué ingenio soberano / dijo: arma virumque cano... / (...) Pues aquel gran Cicerón, / ¿̨no es divino? / (...) ¿Posible es que Cicerón / se condenase, Gonzalo? GONZALO: ¿¿Ahora piensas en eso? FEDUARDO: ¿Pues no es lástima? GONZALO: ¿De qué? FEDUARDO: De ver que un hombre que fue / quien tuvo este imperiio en peso, / quien escribió las costumbres [De officiis], / la virtud, el amistad [De amicitia], / pierda aquella claridad / de las inmortales lumbres. GONZALO: ¡Lleve el diablo a Cicerón, / a Virgilio y a Lucano!/ Comamos que rabio. FEDUARDO: ¡Oh, hermano, / que has nombrado a un gran varón! / Lucano fue aquel sobrino / de Séneca; entrambos son / de España, y así es razón / que honres su ingenio divino" (acto I, Comedias, XIV, p. 27-28).

Cf. todavía, Jameson (1936: 500). Resulta interesante la noticia que nos transmiten los biógrafos de que Lope probablemente a los diez ańos tradujo en verso castellano el poema de Claudiano De raptu Proserpinae (Rennert y Castro 1919: 18-19). Cf. Entrambasaguas (1947).

Lope, como tantos hombres cultos de la época, no sabía griego; a la literatura en esta lengua se acerca por las traducciones latinas o castellanas. Según Classen (2002), Lope debía de tener buen conocimiento de Cicerón. Vid. también Ramos (1995). Cf. Dixon (2005: 96): «... [Lope] tiene asimilado un montón de cultura clásica...». Ello no es contradictorio con la afirmación de que Lope bien pudo servirse en ocasiones de polianteas: vid. González-Barrera (2007). Para un aspecto concreto y fundamental de la cultura clásica de Lope, cf. Romojaro (1991). Cf., además, 
que expresa en su querida lengua castellana, eficaz instrumento de transmisión del hermoso edificio alzado por el Humanismo ${ }^{18}$.

\section{UN PÓRTICO PARA EL TEMA}

\section{I.1 Laus mulierum}

Lope cultiva el tema de la laus mulierum, enfrentada, en la tradición, al resentimiento misógino ${ }^{19}$. Probablemente, la figura femenina que Fray Luis de León traza en La perfecta casada, marcada por la dulzura y generosidad, por

Ramajo (1993, 1996) y Romano Martín (2007).

18. En la dedicatoria a «Lope de Vega, su hijo», en El verdadero amante (¿1585-1589?, pero escrita años después: antes de 1620), dice: «... he visto muchos que, ignorando su lengua, se precian, soberbios, de la latina, y todo lo que está en la vulgar desprecian, sin acordarse de que los griegos no escribieron en latín, ni los latinos en griego. Y os confieso que me causa risa ver algunos hombres preciarse de poetas latinos, y en escribiendo en su lengua parecer bárbaros; de donde conoceréis que no nacieron poetas, porque el verdadero, de quien se dice que ha de tener uno cada siglo, en su lengua escribe, y en ella es excelente, como el Petrarca en Italia, el Ronsardo en Francia y Garcilaso en España, a quien también deben sus patrias esta honra. Y lo sintió el celestial ingenio de Fray Luis de León, que pretendió siempre honrarla, escribiendo en ella, como también le sucedió a Fray Luis de Granada (...)», (Comedias, II, p. 86). Cf. Ramajo (2003), para la apología de las lenguas vulgares en los Siglos de Oro.

El teatro de Lope destila sutilmente sabiduría humanística. Cuando Venturoso se marcha de la casa de su padre putativo, Belardo, no lleva equipaje: «Todo el bien traigo conmigo, / aunque la hacienda dejé...» (El hijo Venturoso, de 1598-1605, Jornada II, Comedias, III, p. 42). Es adaptación del episodio en que el sabio Bías sale desnudo de su ciudad conquistada por el enemigo, y exclama: "... omnia mecum porto mea» (Cicerón, Paradoxa Stoicorum, I, 8). Al mismo pasaje estoico remiten unos versos de otra obra: Doña Elvira, reina madre de Navarra, recibe la recomendación de un "Guarda» de que huya de las manos del rey impostor Sancho; y que huya sin nada, pues sus bienes se guardan en su vientre: el hijo, que, por cierto, al final se convertirá en rey: «ihuye reina!, pues que van / contigo todos tus bienes, / ¿qué tienes tú que dejar, / si llevas al Rey contigo?» (El principe despeñado, de 1602, vv. 493-496). Lope sabe transmutar en pasaje risible la gravedad de un tópico clásico. Así, Julio se extraña de que Serafina viva en una pequeña casa, «porque ¡cómo puede estar / menos que en palacio grave / una mujer donde cabe / mundo, cielo, guerra y mar?». Y su amo le dirá: «Déjate de burlas, loco, / que el hombre es pequeño mundo, / y en este argumento fundo / que este mucho cabe en poco" (El leal criado, de 1594, acto I, Comedias, I, p. 447). Para el tema del microcosmos, cf. Rico (1982). También de manera amable toca Lope un tema serio: el ser humano mira al cielo, y los brutos al suelo, por la diferencia de dignidad: Belisa no quiere que su hija Fenisa levante los ojos del suelo, para proteger su castidad. Ésta replica aguda: «Crio Dios derecho al hombre / porque el cielo ver pudiera; / y de su poder sagrado / fue advertencia singular, / para que viese el lugar / para donde fue criado./ Los animales, que el cielo / para la tierra crio, / miren el suelo..." (La discreta enamorada, Jornada. Comedias, $X V$, p. 877). En efecto: «pecora... natura prona... finxit...» (Salustio, De coniuratione Catilinae, I, 1); a los hombres, en cambio, la misma naturaleza «erexit et ad caeli quasi cognationis docimilique pristini conspectum excitavit» (Cicerón, De legibus, I, 9, 26: 'los alzó y los levantó a la mirada del cielo, como domicilio primero y casi de su familia’: vid. Pabón 1945: 29). A veces, súbitamente, Lope toma algunos versos famosos de poetas antiguos. Así, no faltan ecos del famoso «latet anguis sub herba» (Virgilio, Bucólicas, III, 93). Lupercio piensa que su esposa, Fulgencia, le ha sido infiel, y la increpa: "Calla, / calla, sierpe venenosa, / que entre la yerba se halla» (Los embustes de Celauro, de 1596-1598, acto II, 859-861, p. 95).

19. Para el tema de la alabanza y del vituperio de la mujer, cf. Ramajo (2006: 550-551). 
su fuerza creadora, no sólo en cuanto madre, sino en cuanto conservadora de la vida en la dimensión de preservadora de la armonía y luz de la familia (y de la sociedad), debió de grabarse en la retina de los escritores. Dejemos alguna muestra del tópico en Lope.

Jacinto recibe bienes de Belarda, que le da de comer, cuando desfallecía de hambre, al huir de sus perseguidores, quienes pretendían que se casara con Amaranta. Y exclama:

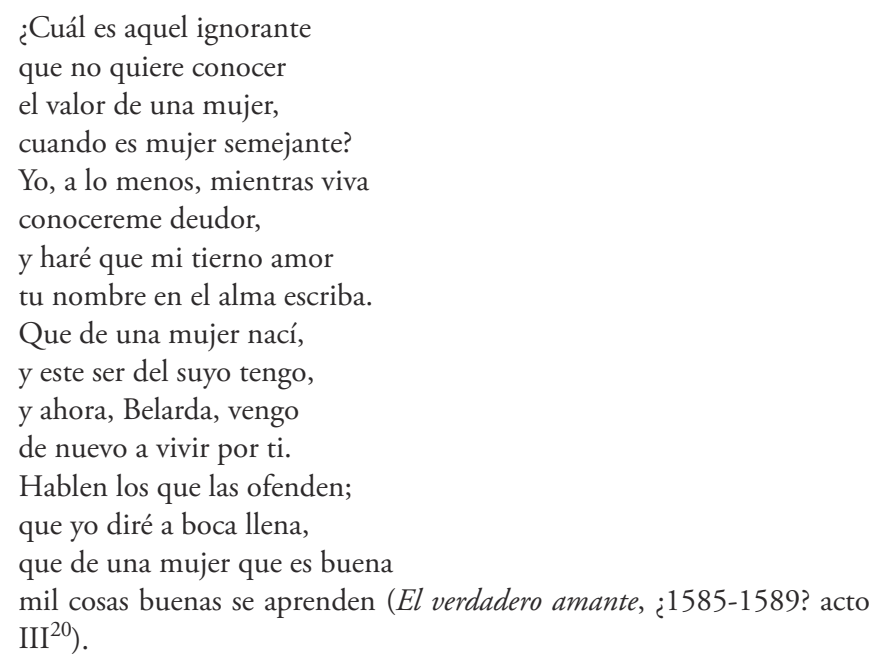

Ahora anotemos otro ejemplo «a lo divino». En la Vida y muerte de Santa Teresa de Jesús (1622), la Envidia, que no es sino el Diablo, establece un catálogo de mujeres virtuosas en el Antiguo Testamento. La Virgen María cierra el catálogo y abre un tiempo nuevo: ella es la más excelente. Pero tras la Inmaculada, han aparecido otras mujeres dotadas de insignes dotes. El Diablo se fija ahora con preocupación en:

$$
\begin{aligned}
& \text { desta que en Ávila llaman } \\
& \text { con gran misterio Teresa, } \\
& \text { que milagrosa y divina } \\
& \text { significa en lengua griega }(\ldots)^{21} \text {. }
\end{aligned}
$$

Y traza enseguida una brevísima biografía de la santa.

Por otro lado, la belleza de la mujer es emanación de la Belleza de Dios. Pero

20. Lope se sirve aquí de una fórmula retórica frecuente en la literatura latina: alii... ego (los que... yo: vid. Ramajo 1994). Vid. Comedias, II, p. 158-159. En La infanta desesperada, de 1588-1595, un duque habla mal de Lavinia, la infanta, porque tiene amores con un príncipe extranjero, Doristán, y, en general, de las mujeres. Pero otro personaje le reprende: «¿Por qué apocas / la virtud de que están llenas [las mujeres]» (Jornada II, p. 138). Vid. el tema en Calderón de la Barca: «No hables mal de las mujeres: / la más humilde te digo / que es digna de estimación, / porque, al fin, de ellas nacimos» (El alcalde de Zalamea, Jornada II, 1612-1615).

21. Cf. Jornada I, vv. 177-180 (véanse los vv. 154-214), Vida y muerte de Santa Teresa, p. 5152. Para la discutida etimología griega de Teresa, vid. el buen resumen de Faure (2007: s. v.). 
de eso se hablará en capítulo posterior dedicado a la dama que «refrena», a la donna angelicata.

\section{I.2 Mujer: debilidad}

Lope recoge una tradición de ambigüedad con respecto a la mujer. Si ella es creadora y conservadora de la vida, no sólo en lo físico, sino también en la armonía social, con todo, los escritores -el propio Fray Luis en La perfecta casada $^{22}$ - insisten en la supuesta debilidad femenina, en lo que se refiere a lo racional. Probablemente, se inserta aquí una línea de pensamiento estoico, en el cual el hombre es el poseedor de la fuerza de la razón, y la mujer, en esa dimensión, se ofrece disminuida con respecto al varón ${ }^{23}$.

Que la mujer, en comparación con el hombre, sea débil, es tópico reiterado, en efecto. El rey Alfonso el Casto sabe que su hermana Jimena ha tenido relaciones extramatrimoniales. Ni siquiera las princesas muestran la fortaleza que se les pide. Y dice el Fénix:

Da mi hermana mala cuenta, mas es mi hermana mujer: mujer es toda flaqueza, que tener sangre de rey no muda naturaleza (Las mocedades de Bernardo del Carpio, 1599-1608, Jornada $\left.\mathrm{I}^{24}\right)$.

\section{I.3 Mujer: su paradójico ser: débil, pero su presencia da ánimos}

Que la mirada de la mujer esfuerce al amante es tópico presente en las Heroidas ovidianas. Leandro ha de nadar el mar frío para encontrar a Hero. Y en sus ojos hallará aliento:

Cum vero possum cerni quoque, protinus addis

spectatrix animos, ut valeamque facis (XVIII, 93-94: "Pero en cuanto apareces a mis ojos, al instante, al contemplarme, me acrecientas los alientos y me haces más fuerte» $)^{25}$.

22. Vid. algunos ejemplos: «... como la mujer sea de su natural flaca y deleznable...» ( $\mathrm{La}$ perfecta casada, cap. I, p. 86); «... siendo de suyo tan flaca...» (cap. I, p. 86); «Porque, si los hombres, que son varones, con el regalo conciben ánimo y condición de mujeres y se afeminan, las mujeres ¿qué serán...?» (cap. VIII, p. 126).

23. Séneca señala que Marcia es mujer especial, por alejarse "ab infirmitate muliebris animi» (Consolatio ad Marciam, I, i). Para este verdadero lugar común de la supuesta debilidad femenina, cf. la buena nota de Viansino (2000: 461-462). Cf. también los nueve estudios incluidos en el vol. coordinado por Calero y Durán López (2002).

24. Obras. XVII, p. 7.

25. También los animales luchan por amor. Y las novillas dan ánimos a los toros con su mirada: cf. Ovidio, Amores, II, xii, 25-26. En El poema de Mio Cid, Rodrigo dice a su esposa Jimena: «créçem’ el coraçón porque estades delant» (Cantar segundo, v. 1655). 
La mora Zayda confía en su amado Gazul:

ZAYDA.- Yo fío de tu valor que has de salir victorioso.

GAZUL.- Pues ¿¿cómo puede ser menos,

si me dan favor tus ojos? (El sol parado, 1596-1603, acto III) ${ }^{26}$.

La confianza será vana: Gazul será derrotado por el Maestre de Santiago, que había conseguido que se parara el sol para abatir totalmente a los musulmanes (estamos en la época de Fernando III el Santo).

\section{Mujeres «... QUE ENCIENDE[N] EL CORAZÓN»}

La mujer se ofrece como objeto de conquista al hombre, cazador insaciable ${ }^{27}$. Esa mujer se figura en símiles de vario contenido semántico: el poeta ahonda, a veces, en la esquividad de la amada (el acercamiento a ella se tińe de tono militar); a veces, en la dulzura femenina.

\section{II.1 Símiles descriptivos de la mujer}

\section{II.1.1 Mujer: muro; ciudad}

La comparación mujer-muro, ciudad amurallada, figura en Ovidio: el poeta ha conquistado a Corina, y se compara con un estratega militar:

Non humiles muri, non parvis oppida fossis

cincta, sed est ductu capta puella meo (Amores, II, xii, 7-8: «No bajos muros, no fortalezas ceñidas con pequeños fosos, sino una joven ha sido conquistada con mi estrategia»).

Lucinda, pastora que ha sido burlada por el rey -desaparecido al alba, tras pasar la noche con ella ${ }^{28}$, declarará:

$$
\begin{aligned}
& \text {... suele uno destos, } \\
& \text { conquistando una ciudad, } \\
& \text { fingir mucha voluntad } \\
& \text { y propósitos honestos; } \\
& \text { jurar en cuanto se ofrezca }
\end{aligned}
$$

26. Comedias, $I X$, p. 85.

27. El amor como caza es otro tópico frecuente en el teatro lopesco. Vid., solamente, $\mathrm{La}$ discreta enamorada, 1604-1608: Belisa previene a su hija: "Decía tu abuela honrada / que una doncella altanera / era en la calle una fiera / de cazadores cercada» (La discreta enamorada, Jornada I, Comedias, XV, p. 878. Cf. Murgatroyd (1984).

28. Los hombres olvidan las promesas y la pasión amorosa una vez saciado el apetito: es tópico antiguo: véanse las quejas de Ariadna en Catulo, nº 64, 143-148. En Lope de Vega se observa el tópico: don Rodrigo pierde interés por la Cava tras haberla forzado, y dice pedestremente: «quien come con mucha furia, I con la misma furia para” (El postrer godo de España, ¿1599-1600?, acto II, Comedias, XI, p. 660). 
y, en ganando la muralla,

salirse de la batalla

antes que Dios amanezca (La fe rompida, de 1599-1603, acto II $)^{29}$.

Lucinda pinta al amante inconstante. En todo caso, ella, «virgo bellatrix»" no es nada débil, pues, se saldrá con su deseo y se casará con el rey.

Es tópico relacionado con otro extraordinariamente frecuente en la tradición literaria, y que merecería estudio aparte: el de la militia amoris $^{31}$.

\section{II.1.2 Mujer: oveja: la huella bucólica y la raíz cristiana}

Como muchos poetas áureos, Lope fue sensible al encanto de la literatura bucólica, particularmente a la virgiliana ${ }^{32}$. En los versos del gran vate mantuano se encontraban matices varios, en particular enlaces y rivalidades amorosas.

Con el símil de mujer=oveja, se canta el amor perdido y el afán de recuperarlo, en la creencia de que la amada, como oveja, es propiedad de su auténtico

29. Comedias, $X I$, p. 46. Acaso variante de este tópico sería la consideración de «una ciudad vista como una novia a cuya mano aspira el sitiador»: vid. Menéndez Pidal (1969: 201), quien ve el origen del tema en los poetas árabes.

30. Cf. Virgilio, Eneida, VII, 805-806: «bellatrix... /... virgo» (el poeta se refiere a Camila, doncella y luchadora).

31. El tema de la militia amoris brota por doquier. Ya Plauto establecía paralelismos entre los dos campos. Dice que el seducido por la meretriz recibirá: "pro equo lectus detur, scortum pro scuto» (Bacchides, I, 72). Vid. Horacio, IV, 1: «Intermissa, Venus, diu / rursus bella moves?...». Propercio piensa que él no nació para la vida militar, sino para "hanc... militiam», para la del amor (Elegías, I, vi, 30). Dido desea que Eneas sea soldado en los campamentos del Amor, a quien se dirige: "castris militet ille tuis» (Heroidas, VII, 32). Cf. Ovidio, Amores, I, ix, 1: «Militat omnis amans et habet sua castra Cupido» (vid. la alusión de un personaje lopesco: «Luego ¿por eso decía / Ovidio que militaba / cualquier persona / que amaba?»: El piadoso veneciano, 1599-1608, acto II, Comedias, XV, p. 524); cf. Amores, I, xiii, 20: «Porrigimus uictas ad tua iura manus» (el amante se entrega rendido al Amor, las manos unidas cual cautivo). En Fernando de Herrera, Algunas obras, Sevilla, 1582, el poeta pretende luchar contra el Amor (véase el léxico bélico): «Las armas, en el templo ya colgadas, / visto, i el azerado escudo embraço, / i en mi venganza salgo a la batalla» (soneto VIII, 9-11, Poesía castellana original completa, p. 366). Vid., de nuevo, Algunas obras: «Mas, al primer sonido del assalto, / desamparo la fuerça, i el escudo / rindo i armas...» (soneto LXVIII, 9-11, Poesía castellana original completa, p. 456). Vid. Don Quijote de la Mancha, I, cap. xxxiiii: «Finalmente, a él le pareció que era menester (...) apretar el cerco a aquella fortaleza, y, así, acometió a su presunción con las alabanzas de su hermosura, porque no hay cosa que más presto rinda y allane las encastilladas torres dela vanidad de las hermosas que la mesma vanidad...» (p. 396); vid. Don Quijote de la Mancha, I, cap. xxxiiii: "por la mañana [el amor] suele poner el cerco a una fortaleza y a la noche la tiene rendida» (p. 401). Vid. Lope de Vega: «Amor es guerra, y cuanto piensa, ardides» (Peribáñez y el Comendador de Ocaña, de 1613, acto II, 1811, p. 94).

32. Habría que trazar un inventario de la huella de las Bucólicas virgilianas en el teatro de Lope. Eco de la Bucólica II de Virgilio -sirva de ejemplo-, tamizada acaso por Garcilaso, se encuentra en este pasaje, en que el pastor Frondelio manifiesta su amor hacia Albania: «No soy tan feo que dejarme puedas / por ese vil, que hablando de él me canso [el pastor Jacinto]; / que hoy me vi el rostro entre estas arboledas, / en el cristal de un arroyuelo manso" (La pastoral de Jacinto, de 1588-1598, acto I, 778-781, p. 83-84). 
pastor. Si el sustrato bucólico es obvio, acaso en Lope también se esconda la huella evangélica de la ovis perdita (Mateo, 18, 10-14; Lucas, 15, 1-7) y del

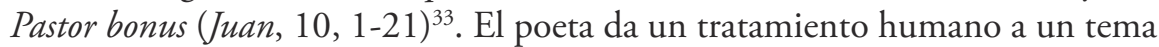
«divino». Estos textos de Lope se hermanan, claramente, con los sonetos del llamado ciclo de «mansos» (a uno de los cuales nos referiremos enseguida), en los cuales figura este símil ${ }^{34}$.

En nuestro corpus estudiado hallamos dos ejemplos del símil. En el primero, Nuño, labrador convertido en noble, y luego, por la cólera del rey Alfonso el Casto, devuelto a su primera condición, marcha decidido a la corte, desde el campo, en busca de su amada Nise, pretendida por dos cortesanos:

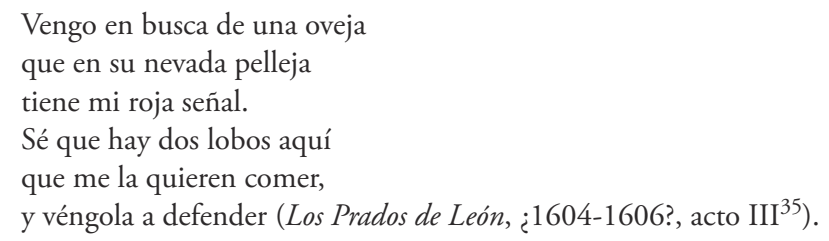

En el segundo caso, Belardo dedica a su amada Jacinta un soneto de «mansos». Lope lo incluirá también en las Rimas (1602) -nosotros reproducimos el texto de la comedia que citamos a continuación- ${ }^{36}$ :

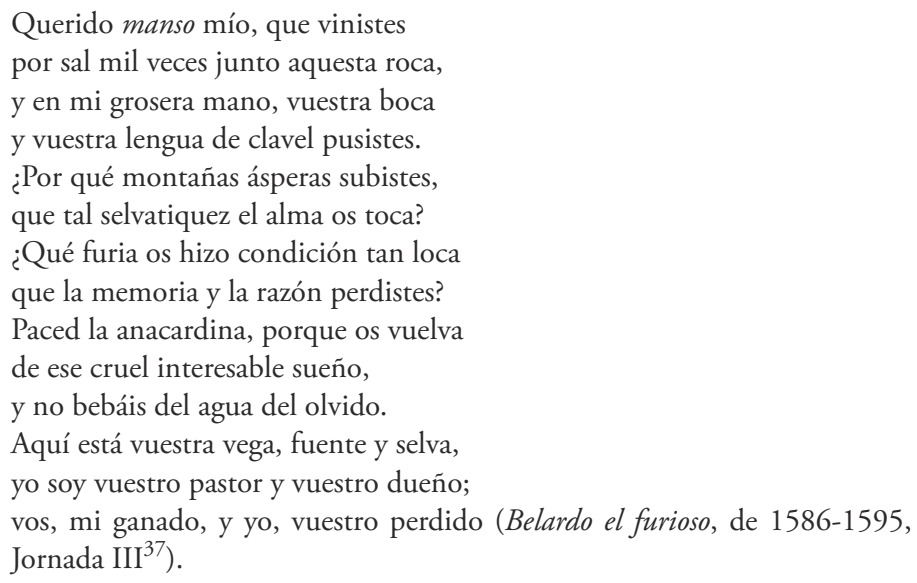

33. Lope de Vega leyó, sin duda, el apartado de «Pastor», en De los nombres de Cristo, de Fray Luis de León (lib. I).

34. Vid. Pedraza (1993: 594) y Carreño (1998: 359 y 1003-1004). Vid. también Lázaro Carreter (1966), Lara Garrido (1983), y Larsen (1999).

35. Comedias, XIV, p. 861-862.

36. Para la cuestión ecdótica, vid. la ed. de Carreño (1998: 897).

37. Comedias, II, p. 538.En Los locos de Valencia, de 1590-1595, no se desarrolla el tema: el despechado Floriano, abandonado provisionalmente por su amada Erifila, dice: «Idos con Dios, mansa oveja» (Acto III, 2449, p. 299). 


\section{II.2 Armas de mujer}

\section{II.2.1 Ojos homicidas}

La mirada, visus, es el primer y fundamental peldaño de la lineae amoris, que se desgranan en cinco pasos, según quiere el gramático Donato: visus, alloquii ('coloquios'), tactus, osculi, coitus ${ }^{38}$.

La anotación del poder «matador» o vulnerador de la mirada es de estirpe medieval. En el Libro de Buen Amor se dirá en el retrato de doña Endrina: "Con saetas de amor fiere quando los sus ojos alça» (653d). Y, sin duda, cosecha apreciable podría encontrarse en una peregrinación por los Cancioneros. En el llamado Cancionero de Palacio, figura la siguiente Canción de Diego Furtado de Mendoza, que comienza: «Ya con tanta fermosura / matades a quien vos mira, / la virtud qu'en vos espira / engendra mucha locura ${ }^{39}$. No falta su presencia en la lírica tradicional:

$$
\begin{aligned}
& \text { Ojos matadores } \\
& \text { tenéis, señora, } \\
& \text { ¿cómo la justicia } \\
& \text { no los ahorca? }
\end{aligned}
$$

El tópico de los ojos homicidas se aprecia bien en estos requiebros que Lisardo dirige a Juana, mujer disfrazada:

«... como a quien veis matáis,

espantáis como la muerte...» (El mesón de la corte, ¿1588?-1595, Primera Jornada $)^{41}$.

O en los que dirige Leandro a Violante, disfrazada de labradora:

¡Ojos bellos, labradores,

puede ser que allá labréis,

pero acá, no lo dudéis,

que matáis almas de amores! (Las ferias de Madrid, ¿1585-1589?, Jornada $\mathrm{I}^{42}$ ).

38. Cf. Ramajo (2002: 10).

39. Vid. Cancionero de Palacio, ed. de Ana Ma Álvarez Pellitero, Salamanca, Junta de Castilla y León, 1993, p. 9. Vid. Juan de Mena: «Vuestros ojos que miraron / con tan discreto mirar, / firieron e non dexaron / en mí nada por matar» (vv. 1-4, en Juan de Mena, Obras completas, p. 2). Vid. Hernando de Acuña, Égloga [IV], vv. 266-267: «... de aquellos ojos / que matan y dan vida en un instante» (Varias poesías, p. 127). Vid., todavía, Meléndez Valdés: «Tus lindos ojuelos / me matan de amor» («A unos ojos», en "Letrillas», Obras completas, ed. de Antonio Astorgano Abajo, Madrid, Cátedra, 2004, p. 214).

40. Vid. Cancionero tradicional, $\mathrm{n}^{\circ} 823$; cf.también el $\mathrm{n}^{\circ} 406$.

41. Comedias, II, p. 9. En esta comedia se agolpan las peripecias en el espacio del mesón, verdadera unidad de lugar. Que el mesón sea lugar privilegiado para aventuras, amoríos y engaños, se aprecia también en La noche toledana, de 1605. Ténganse presentes, además, las ventas del Quijote. No siempre incumple Lope, como se ve, todas las unidades teatrales. En La noche de San Juan, de 1631, dice al terminar: «Aquí la comedia acaba / de la noche de San Juan, / que si el arte se dilata / a darle por sus preceptos / al poeta, de distancia, / por favor, veinticuatro horas, / ésta en menos de diez pasa» (acto III, 3030-3036, p. 150).

42. Comedias, II, p. 378-379. 
En la corte del emperador otomano Selín, unos cautivos españoles cantan la hermosura de Rosa Solimana:

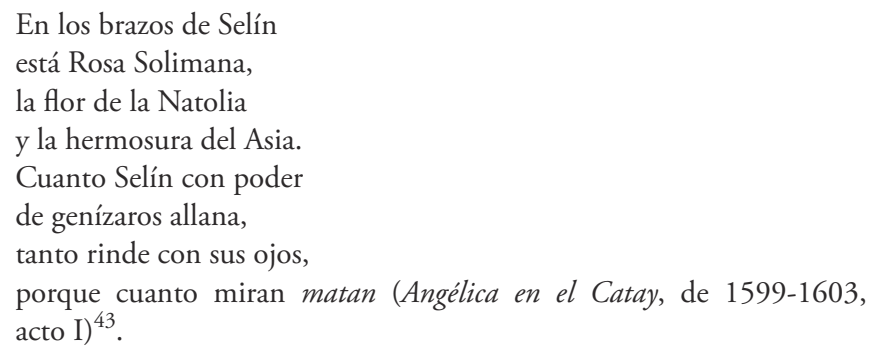

En un billete amoroso sigue el tópico don Alonso, El caballero de Olmedo (¿1620-1625?):

Si matas con los pies, Inés hermosa, ¿qué dejas para el fuego de tus ojos? (vv. 515-516) ${ }^{44}$.

A veces, el galanteo se mezcla con la seriedad. Esas mujeres alabadas pueden ser, en efecto, homicidas, con inconsciencia de los varones. En El postrer godo de España (1599-¿1600?), el tópico se torna trágico. El árabe Abraydo se siente atraído por la hermana de Pelayo, Somira. Pero ésta lo rechaza con la espada. Aquel dirá: «Para matar, mirar basta» ${ }^{45}$. Pero la muerte se tornará real. Somira es una «virgo bellatrix» que mata al amante para defender la honra.

Una situación un tanto semejante se inserta en Las pobrezas de Reinaldos (1599). La mora Armelinda odia a Florante, cortesano de Carlomagno, que ha provocado la ruina de Reinaldos. Armelinda, aunque mujer, está dispuesta a matar a Florante (no llegará a hacerlo). Éste intenta una salida de galanteo:

Si has de matar con los ojos, yo me rindo, no me mates (Las pobrezas de Reinaldos, acto II) ${ }^{46}$.

En La moza de cántaro (1625-1627) también se juega entre el galanteo y una realidad sangrienta. Don Juan galantea a doña María. Ésta ha matado a un hombre, don Diego, para defender el honor de su padre. Su amado don Juan no lo sabe, y no alcanza la profundidad de lo que dice la mujer:

\author{
DOÑA MARÍA \\ Pues vos no me conocéis. \\ ¡Por Dios, que algún hombre he muerto \\ aquí donde me miráis!
}

\footnotetext{
43. Comedias, X, p. 483.

44. El caballero de Olmedo, p. 127. El "fuego de tus ojos» se relaciona con la frecuente comparación de los ojos con el sol o con los astros, como ya en Ovidio: «oculos, sidera nostra, tuos» (Amores, II, xvi, 44).
}

45. Comedias, XI, p. 699.

46. Comedias, VI, p. 356. 


\section{DON JUAN}

Con los ojos, yo lo creo (Jornada II, 1445-1448) ${ }^{47}$.

Leonarda, la serrana de la Vera, será capaz de matar a algunos transeúntes. Sus ojos se acomodan bien a sus acciones. Antes de que se lance al monte, le dirá su amado, y luego marido, don Carlos:

... a esos ojos matadores,

quiero comprar mil amores (La serrana de la Vera, de 15951598 , acto I $)^{48}$.

\section{II.2.2 Ojos: espiritus}

Los ojos son elementos comunicativos privilegiados. El amor penetra por ellos. Mirar y amar es todo uno, en Virgilio y en Ovidio ${ }^{49}$. Sin duda, en Lope influye el famoso soneto VIII de Garcilaso: «De aquella vista pura y excelente / salen espirtus vivos y encendidos, / y siendo por mis ojos recebidos, / me pasan hasta donde el mal se siente» $(1-4)^{50}$. Pero es claro que el tópico viene de más lejos. Véanse los siguientes versos de Dante: «De li occi suoi, come ch' ella li mova, / escono spiriti d'amore inflammati, / che feron li occhi...» (vv. 51-53, en Vita nuova, cap. XIX).

Lope cultiva con mucha frecuencia el tópico. Así dice el Rey en El molino (a. 1596):

si es amor un espiritu que pasa

por los ojos al alma, y la sujeta... (I Jornada ${ }^{51}$ ).

Y la Reina en Las burlas de amor (1587-1595):

Que amor

al alma por ellos [por los ojos] entra I) ${ }^{52}$.

y que abrasa lo que encuentra (Las burlas de amor, Jornada

47. La moza de cántaro, p. 171.

48. Comedias, V, p. 7. Para la relación del tema con el de las serranas bravas, véase la letrilla de Lope que comienza: «Salteáronme los ojos / de la mozuela; / diles más que pedían, / ¿¿de qué se quejan?» (Poesias líricas, I, p. 66). En Las justas de Tebas y reina de las Amazonas, a. 1596, tales mujeres «matan con brazo varón, / no con ojos de mujer», según dice uno de los personajes (I Jornada, Comedias, I, p. 744).

49. Medea le dice a Jasón: «Et uidi et perii» (Heroidas, XII, 33): es reelaboración a partir de Virgilio: «ut uidi, ut perii» (Bucólicas, VIII, 41).

50. Obra poética y textos en prosa, p. 22.

51.Comedias, II, p. 284. Los ojos constituyen un excelente lenguaje no verbal. Téngase presente la huella de Ovidio. Dirá el Rey en El molino, a. 1596, a propósito de la duquesa Celia: «que los ojos (...) suelen / ser lenguas del amor, cuando la lengua / está atada por miedo o por el tiempo" (Jornada II. Comedias, II, p. 318).

52. Comedias, II, p. 562. 
Un pastor ha contemplado a los amantes Albanio e Ismenia expresar su amor por los ojos:

Vi los espiritus vivos

que de los ojos salían,

como rayos atractivos,

que poco a poco encendían

los corazones cautivos (Los amores de Albanio y Ismenia, de 1590-1595, Jornada I $)^{53}$.

En La noche de San Juan (1631), doña Leonor refiere a su criada la teoría de la transmisión del amor por los ojos:

Dicen los que saben desto,

Inés, que el amor se causa

de unos espiritus vivos

que los ojos de quien ama

a los opuestos envían,

y como veneno abrasan

de aquellas sutiles venas

la sangre más delicada (acto I, 57-64) ${ }^{54}$.

El tópico se repite una y otra vez. Dice don Alonso:

De los espiritus vivos

de unos ojos procedió

este amor, que me encendió

con fuegos tan excesivos (El caballero de Olmedo, ¿1620-1625?, vv. $11-14)^{55}$. El caballero Laurencio pretende mostrar a la necia Finea el proceso del
enamoramiento:

Destos mis ojos

saldrán unos rayos vivos,

como espiritus visivos,

de sangre y de fuego rojos,

que se entrarán por los vuestros (...).

Son los espíritus nuestros,

que juntos se han de encender

y causar un dulce fuego... (La dama boba, de 1613, acto I, 789$798)^{56}$.

53. Comedias, III, p. 554-555.

54. La noche de San Juan, p. 47.

55. El caballero de Olmedo, p. 106 (cf., en ese mismo lugar, la nota de Rico 1991, y cf. también las p. 22-23 del mismo trabajo, en que se anota la importancia para el tópico de Marsilio Ficino).

56. La dama boba, p. 94-95. Para Santolaria (2003: 183) este pasaje tiene la huella de Aquiles Tacio, Leucipa y Clitofonte, I, 9. 


\section{II.2.3 Piel: Color moreno}

En el corazón de la Antología Palatina brota ya una reivindicación de la belleza de lo moreno. Asclepíades de Samos (ss. IV-III a. C.) se derrite por la morena Dídime:

Con su palmito me sedujo Dídime, y yo, jay de mí!, me derrito como cera junto a la llama viendo su hermosura. ¿Y qué si es negra? También lo son los carbones. Y cuando los encendemos resplandecen como cálices de rosas ${ }^{57}$.

Virgilio, que se formó como poeta neotérico, empapado de gusto helenístico, dejó apuntados temas y formas luego reelaborados por poetas posteriores. En la égloga II, Coridón no desdeña a Menalcas, "quamuis ille niger» (v. 16); y en la X, Galo preferiría al «fuscus Amyntas» (38) antes que sufrir insoportablemente por la esquiva Licoris.

A Ovidio le agradan todas las mujeres:

\section{Non est certa meos quae forma invitet amores (...). \\ Sive aliqua est oculos in se deiecta modestos, uror et insidiae sunt pudor ille meae; \\ sive procax aliqua est, capior qua rustica non est} spemque dat in molli mobilis esse toro... (Amores, II, iv, 9-14: «No tengo hermosura concreta que me impele al amor (...). Que una baja hacia sí sus timidos ojos, me abraso, y su pudor me sirve de prisión; que una es desvergonzada, me seduce el que no es indocta, y me engolosinan sus movimientos en el suave lecho»).

Y sigue enumerando tipos diversos de mujeres, de acuerdo a cualidades morales o físicas. También le agradan las morenas:

Candida me capiet, capiet me flava puella,

est etiam in fusco grata colore venus (Amores, II, iv, 39-40: «La blanca me seducirá, me seducirá la joven de tez rojiza, y también en color oscuro se esconde grato atractivo»).

Safo, en carta a Faón, defiende su morenez:

Candida si non sum, placuit Cepheia Perseo

Andromede, patriae fusca colore suae.

Et variis albae iunguntur saepe columbae... (Ovidio, Heroidas, $\mathrm{XV}, 35-37)^{58}$.

57. Vid. Asclepiades de Samos. Epigramas y fragmentos, p. 173. Para la apología de lo moreno, cf. las oportunas notas del editor Guichard (2004: 172-173). El lib. V de la Antología Palatina puede leerse también en la buena traducción de Cristóbal Rodríguez Alonso (vid. p. 100 para el epigrama de Asclepíades). En ese mismo libro, véase el epigrama de Filodemo: «Menuda y negruzca es Filemón, pero más rizosa / que el apio...» (Rodríguez Alonso, p. 76). Para la Antología Palatina en Espańa, cf. López Poza (2005: vid. p. 61-64, para lo referente a Lope de Vega).

58. Vid. la traducción de Francisco de Rioja: «Si no soy blanca, Andrómeda a Perseo / agradó, aunque en color patrio teñida» (Poesía, «Traducciones», II, vv. 4-5, p. 242: vid. la nota de López 
Pero seguro que las letras clásicas no influyeron sólo en la reivindicación de lo moreno como elemento bello. La sponsa del bíblico Cantar de los Cantares debió de pesar en la sensibilidad de los escritores espańoles. Recordarían aquel versículo famoso: «Nigra sum, sed formosa» $(\mathrm{I}, 4)^{59}$.

No faltará, en efecto, la reivindicación de lo moreno en las letras españolas. Así dirá Pedro de Padilla, Laberinto amoroso:

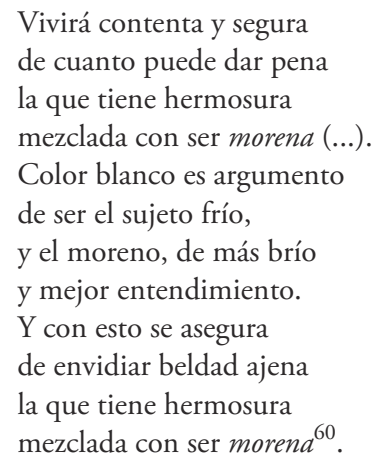

Lo moreno, sin duda, aporta, en ocasiones, una nota de sensualidad en la configuración del personaje femenino. En cambio, el cabello rubio parece acentuar el carácter angélico de la dama ${ }^{61}$.

El amante de Lope, ansioso por cualquier tipo de mujer, caerá en la red de la monogamia, pero, como cazador, acechará presas varias. La turbulencia pasional del paganismo parece hincarse en el alma de los amantes ${ }^{62}$. Teodoro, en la línea del pensamiento ovidiano, exclamará de manera explícita lo que otros personajes masculinos callan:

Bueno). Pero parece que el canon estético está presidido por la primacía de lo rubio. Ariadna se derrite por Teseo, «flauo... hospite» (Catulo, $\mathrm{n}^{\circ}$ 64, 98); Medea dirá de Jasón: «Cur mihi plus aequo flaui placuere capilli» (Heroidas, XII, 11). Vid. La Celestina, "primer auto»: "Comienço por los cabellos. ¿Ves tú las madexas del oro delgado que hilan en Arabia?» (Comedia o Tragicomedia de Calisto y Melibea, p. 230). Vid. también Marcial, I, 115, donde confiesa su amor por una mujer nocte nigriorem ('más negra que la noche').

59. Fray Luis dejará alguna anotación sobre lo moreno: «... las [mujeres] de buenas figuras, aunque sean morenas, son hermosas, y no sé si más hermosas que siendo blancas; las de malas, aunque se transformen en nieve, al fin quedan feas» (La perfecta casada, XI, p. 142).

60. Laberinto amoroso, p. 96-97.

61. La relación entre la etopeya angelical y la prosopografía rubia y clara se aprecia nítida en Garcilaso, Égloga II, 19-21: «iOh hermosura sobre’ 1 ser humano, / oh claros ojos, oh cabellos d'oro, / oh cuello de marfil, oh blanca mano!».

62. Fedra, ante Hipólito, excusará su pasión inconveniente por el influjo de un destino genético, generis fato, que ha llevado a su familia a entregarse a pasiones varias (Heroidas, IV, 55); también Helena recibe una herencia de pasiones (Heroidas, XVI, 293-294). Pero ello no quiere decir que en ese mismo paganismo no se busque el amor sólido y duradero. Así, en las Elegías, I, iv, Propercio recibe la instigación de una tal Baso para pensar en multas... puellas (1); pero él quiere permanecer firme en el servitium amoris a Cintia, en su acostumbrado servicio: «hoc... assueto... servitio» (v. 4). 


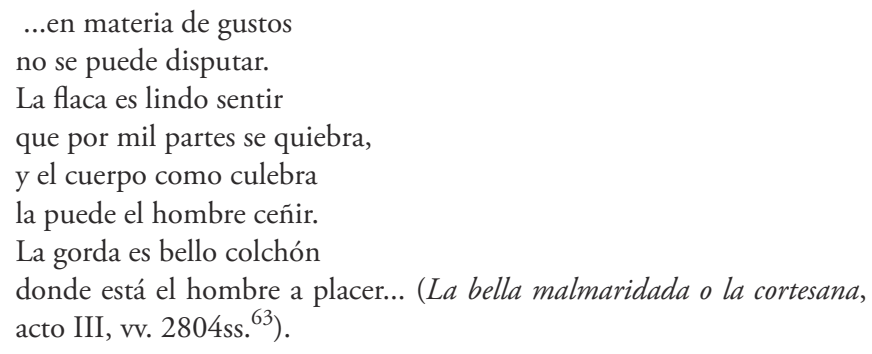

Lope, tan parecido a Ovidio, gusta de todas las mujeres, y no desprecia, en coherencia, lo moreno.

Y el gusto por el cuerpo atezado brotará con alguna reiteración en su teatro. Así, en Servir a señor discreto (1610-1618) figura una criada, Elvira, que es mulata. Se casará con Girón, el criado de don Pedro, caballero enamorado de su dama, doña Leonor. También se casarán los dos señores mencionados. En un par de veces se realiza un elogio de lo moreno.

Dirá la propia Elvira:

... yo tengo por muy bueno

mi color porque el moreno

dicen que a los hombres mata (acto I, 539-541) ${ }^{64}$.

Don Pedro precisará:

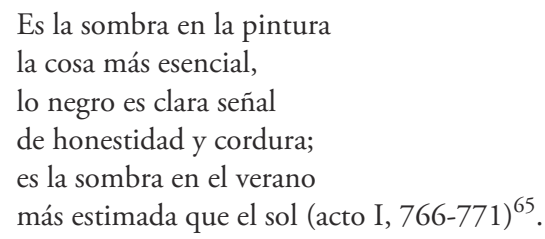

A veces, no se hace un elogio de la tez oscura, pero se anota que su existencia no borra la hermosura de algún ser particular (como hacía, por otro lado, el Cantar de los Cantares). En una letrilla Lope cantaba: «Blanca me era yo / cuando entré en la siega; / diome el sol y ya soy morena.... ${ }^{66}$. En estos versos la mujer disculpa su transitorio color, como hacía la muy citada esposa del Cantar: "Nolite me considerare quod fusca sim, / quia decoloravit me sol» (I, 5). Lope,

63. Cf. p. 136.

64. Servir a señor discreto, p. 119.

65. Servir a señor discreto, p. 138. Lope establece aquí una relación con la pintura, cara en el ambiente de enlace entre pictura y poesis. Vid. Aurora Egido (1990).

66. Poesías líricas, t. I, p. 61. La letrilla de Lope tiene un aire inequívocamente popular: véase la siguiente cancioncilla tradicional: «Aunque soy morena / blanca yo nací; / guardando el ganado / la color perdì» (Cancionero tradicional, nº. 949). En la lírica tradicional, en efecto, se disculpa o incluso se valora el color moreno: vid. Cancionero tradicional, núms. 459, 637 y 950. 
además, se introduce en otra senda que más tarde surcaremos: la descripción de la belleza de la mujer labradora ${ }^{67}$.

El elogio puede ser de mujer o de hombre. De hombre se da en Los palacios de Galiana (no posterior a 1602). Un cautivo, Nizardo, alabará a uno de los nobles de su misma religión, el cristianismo:

«Jiménez de Estúñiga es hombre, aunque moreno, galán..." (Los palacios de Galiana, acto I) ${ }^{68}$.

Don García, ante el retrato de una antigua enamorada, dirá:

«Era un poquito morena,

pero con lindas facciones» (Santiago el Verde, de 1615, acto II, $1604-1605)^{69}$.

Eficaz abogado de lo moreno es el hecho de que haya imágenes de la Virgen de ese color. Por eso el Alcaide que da título a la obra rezará:

¡Virgen de Atocha morena,

pero, aunque morena, hermosa...! (El alcaide de Madrid, de 1599, Jornada I $)^{70}$.

\section{II.2.4 Presencia y pisadas de la mujer}

El que la llegada de la amada reverdezca la naturaleza, o con más precisión, que sus pies hagan brotar las tierras, es tópico que acaso remonte a Hesíodo, Teogonía, 194-195, quien canta el nacimiento de Afrodita, de la espuma del mar, y su llegada a las costas de Chipre, en las que «la hierba renace bajo sus pies ligeros ${ }^{71}$. La presencia o ausencia de la mujer o del amado transforma positiva o negativamente el espacio. Virgilio dirá en la Bucólica VII: «... at si formososus Alexis / montibus his abeat, videas et flumina sicca» (55-56: "...pero si el hermoso Alexis se aleja de estos montes, verás hasta los ríos secos”); y en la misma obra: "Aret ager; vitio moriens sitit aeris herba [...]; / Phyllidis adventu

67. La segadora de nuestro poeta es de estirpe bíblica, según hemos visto, pero en ella también parece unirse el eco horaciano de la "perusta solibus / pernicis uxor Apuli» ('la esposa, abrasada por los soles, del ágil habitante de Apulia'), Epodos, II («Beatus ille», 41-42).

68. Obras, XX VIII, p. 372.

69. Santiago el Verde, de 1615, p. 73. En Las paces de los Reyes y judia de Toledo, de 1610-162, Raquel menosprecia la belleza de la reina dońa Leonor, por venir del norte. Parece que va a haber un elogio de lo moreno, pues tal mujer ensalzará la belleza espańola, la suya ( «... aunque no soy / cristiana, soy española», vv. 1139-1140); pero la cuestión no resultará tan antitética, pues la propia judía Raquel también es de piel blanca («de pario mármol», v. 1244). Véase el pasaje en que Raquel habla con su hermana Sibila: «¿Es posible que te agrada / aquella nieve del norte? / ¿Qué cosa habrá que reporte, / con una hermosa helada, / el gusto de quien la mira? (...). / En España vive Amor; / su brío y gusto merece / que reine Venus en ella...» (acto II, 1124-1136, Las paces de los Reyes y judía de Toledo, p. 174).

70. Comedias, VI, p. 73. Otra vez la huella de «nigra..., sed formosa».

71. Cf. Ramajo (2008: 188-189). 
nostrae nemus omne virebit..." (Bucólicas, VII, 57-59: "El campo se quema; la hierba muere seca por falta de aire [...]. Pero todo el campo reverdecerá si Filis torna"). Petrarca anotará la fuerza creadora de los pies de la amada: "Come "l candido pie" per l'erba fresca / i dolci passi honestamente move, / vertú che 'ntorno i fiori apra et rinove, I de le tenere piante sue par ch' esca».

Las pisadas de la mujer hacen brotar flores y plantas, en efecto. Lleguemos a Lope de $\mathrm{Vega}^{72}$. Bandalino imagina la transformación de las flores si pasa su amada Feliciana:

Flores reverdeced; aspirad ámbar;

si ha puesto en vos sus plantas la flor mía,

más bellas que la misma primavera (El maestro de danzar, de 1594, II Jornada ${ }^{73}$ ).

Venturoso, en apariencia pastor, observa la llegada de su amada Florinda:

¡Ay de mí!, que al campo sale

para, como suele hacer

las espinas florecer

donde las plantas señale,

que, humilladas y floridas,

muestren que quien ha pasado

y florecido y pisado $\left.\mathrm{II}^{74}\right)$.

es señora de mil vidas (El hijo Venturoso, de 1598-1605, Jornada

Albanio ve la llegada de su amada:

La hierba que reverdece

me ha dicho que viene aquí,

que para avisarme a mí

todo se alegra y florece (Los amores de Albanio y Ismenia, de 1590-1595, Jornada II) ${ }^{75}$.

En esa misma comedia podrá contemplarse el tópico al revés. La ausencia de Ismenia arruinará la naturaleza (reverbera el eco de la Bucólica VII de Virgilio, citada):

72. Vid. Góngora: «Al tramontar del sol, la ninfa mía, / de flores despojando el verde llano, / cuantas trocaba la hermosa mano, / tantas el blanco pie crecer hacía» (Sonetos completos, núm. 55, vv. 1-4, p. 120).

73. Comedias, I, p. 614. También el tópico brota en Calderón de la Barca. Don Félix habla del poder de las pisadas de una mujer: "porque al pequeńo contacto, / flores produjo fragantes / tantas la arena...» (Calderón de la Barca, Casa con dos puertas, mala es de guardar, Jornada I, Obras selectas, p. 117).

74. Comedias, III, p. 42-43. El término señora aplicado a la amada viene del domina de la tradición elegíaca: cf. Ovidio, Amores, II, xiii, 16; II, xv, 7; II, xvi, 20; III, ii, 62. Y se mantiene en la lírica latina medieval: cf. Carmina Burana: «Cur suspectum me tenet domina» (v. 1, en The Oxford Book of Medieval Latin Verse, ed. de F. J. E. Raby, reimpr., Oxford, at the Clarendon Press, 1984, p. 317). Pero complétese la cuestión con Ramajo (2006: 40).

75. Comedias, III, p. 582. 
¡Seco, agostado río;

monte espinoso que en el fértil mayo

pareces seco estío;

flores cubiertas de mortal desmayo,

ya el cielo no os esmalta

después que Ismenia de vosotras falta! (Los amores de Albanio y

Ismenia, de 1590-1595, Jornada III) ${ }^{76}$.

El Comendador de Ocaña imagina la floración provocada por las pisadas de la labradora Casilda:

Yo vi los verdes prados

llamar tus plantas bellas, por florecer con ellas,

de su nieve ${ }^{77}$ pisados... (Peribáñez y el Comendador de Ocaña, de 1613 , acto I, 534-537) ${ }^{78}$.

Tello finge que su amo don Alonso ha compuesto un poema de exaltación a doña Inés, del que reproducimos algunos versos:

... después que las bellas

plantas de Inés goza el valle,

tanto florece con ellas,

que quiso el cielo trocalle

por sus flores sus estrellas (El caballero de Olmedo, ¿1620-1625?, vv. $1113-1117)^{79}$.

El cortesano Otón queda prendado de Lisarda, labradora, y la requiebra con halagos tópicos:

Ni la gracia del Rey, ni cuanto puede dar el imperio sumo de la tierra a la imaginación que a todo excede, estimo como el pie con que floreces estos dichosos campos, nueva Flora, que, con pisallos, de oro los guarneces (El villano en su rincón, de 1614-1615, acto II, 1311-1316) $)^{80}$.

76. Comedias, III, p. 608. A veces, las plantas de la amada producen otras transformaciones. Así requiebra Sancho a Elvira, en El mejor alcalde, el rey: «Ayer las blancas arenas / deste arroyuelo volviste / perlas, cuando en él pusiste / tus pies, tus dos azucenas...» (acto I, 31-34: p. 62). La metamorfosis se produce, a veces, por la presencia de la mujer. Lisardo pretende a Teodora, cuya presencia transforma el espacio: «... El día / que vos nos hacéis favor, / Teodora, un jardín volvéis / toda esta casa, un hibleo / campo, donde a mi deseo / tantas flores ofrecéis» (Santiago el Verde, acto I, 167-172, p. 17). Angélica metamorfosea el lugar en el que se encuentra. Dice Reinaldos: «... y estén ciertos / esos ojos, que hacen prados / estos barbechos desiertos...» (Angélica en el Catay, acto II, Comedias, X, p. 716).

77. La nieve de los pies es, obviamente, otro tópico: cf. Góngora, Romance de Angélica: «El pie calza en lazos de oro, / porque la nieve se goce...» (estr. 27; vid. Alonso (1967: II, 39).

78. Peribáñez y el Comendador de Ocaña, p. 35.

79. El caballero de Olmedo, p.150.

80. El villano en su rincón, p. 139. 
El pastor Belardo alaba así a Angélica:

De mañana andáis por el campo ya ${ }^{81}$, y él, que agradecido está, se viste de verde y grana ${ }^{82}$.

Que entre la yerba menuda se levantan rosas tantas, que ser desas bellas plantas o del alba, pongo en duda (Angélica en el Catay, de 1599-1603, acto II $)^{83}$.

En El Amor enamorado (1635) figura el tópico dos veces, y ambas, referido a Sirena, de la que se enamoran el pastor Alcino (a la postre su esposo) y el propio Cupido (de aquí el título de la comedia: El Amor enamorado). Alcino dice:

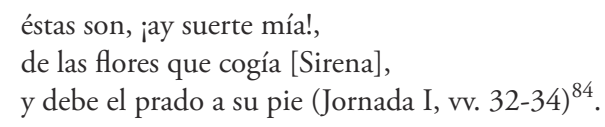

Cupido requiebra a la pastora con la misma idea:

\author{
¡Oh, bellísima Sirena! \\ No sin causa tan amenos \\ hallé los prados [de] Arcadia, \\ que obedientes florecieron \\ a la estampa de tus pies (Jornada III, vv. 2378-2381) ${ }^{85}$.
}

El tópico se diviniza en San Isidro Labrador (¿1604-1606?). Los ángeles labran, en lugar del santo, y todo lo transforman con sus pisadas y su presencia. El pasaje que reproducimos tiene un aire órfico. El río Manzanares se personifica a la manera clásica ${ }^{86}$. Dice San Isidro:

¡Campos de Madrid dichosos, con los ojos en los pies

81. Es tópico la coincidencia entre la salida del sol y la amada. Vid. Fray Luis de León: «Agora con la aurora se levanta / mi Luz...» (soneto III, 1-2, Poesía, p. 161; cf. la nota de Ramajo 2006: 161). Vid. Góngora, en el soneto que comienza: «Tras la bermeja Aurora el Sol dorado / por las puertas salía del Oriente, / ella de flores la rosada frente...» (Sonetos completos, n. 54, vv. 1-3, p. 119).

82. Acaso eco lejano de un virgiliano: "Largior hic campos aether et lumina vestit» (Eneida, VI, 640: cf. Ramajo 2006: 22).

83. Comedias, $X$, p. 729.

84. El Amor enamorado, p. 66.

85. El Amor enamorado, p. 195.

86. Sobre la cuestión, vid. Lope de Vega: «Allá en la gentilidad / dioses los ríos llamaron...» (El hijo Venturoso, de 1598-1605, Jornada II, Comedias, III, p. 37). Cf. Eneida, VIII, 31-33: el dios Tíber se le aparece a Eneas: "Huic deus ipse loci, fluvio Tiberinus amoeno / populeas inter senior se attollere frondes / visus..." ('le pareció que el mismo dios del lugar, el Tíber, con su ameno curso, se levantaba entre las hojas de los álamos'). 


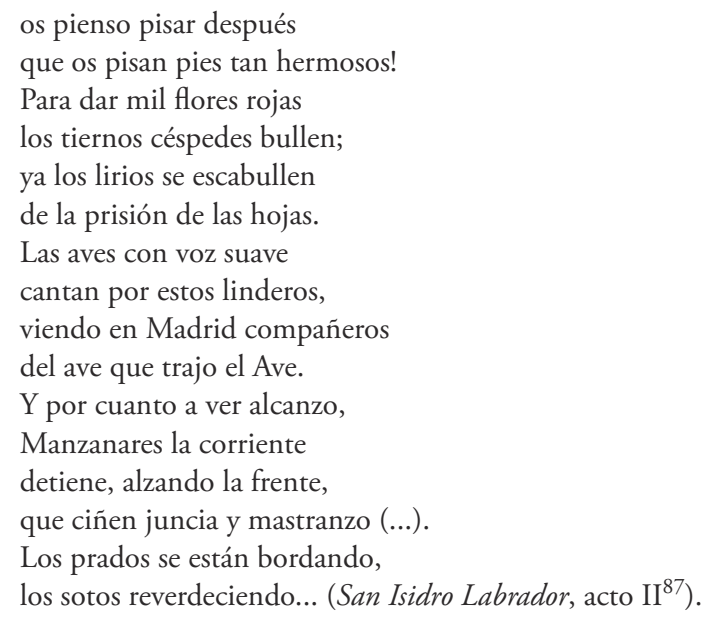

\section{MUJER «...QUE LO [EL CORAZÓN] REFRENA»}

\section{III.1 Donna angelicata}

«... la mujer es una criatura semidivina cuya misión es derramar la salvación y cuyos ojos infunden paz y amor, sembrando en el corazón del amante la nostalgia del paraíso» (Luis Alberto de Cuenca ${ }^{88}$ ). Muy fecunda ha sido esta concepción amorosa, cultivada en el siglo XIII, en Italia, en el llamado Dolce Stil Novo ${ }^{89}$. La concepción, con el trasiego entre los escritores, se fosilizará, y la mujer recibirá el calificativo de ángel de manera mecánica ${ }^{90}$. Pero el tópico vive, al menos, hasta el siglo XIX ${ }^{91}$. Lope lo cultivará con profusión. Dejaremos aquí algunas muestras, sin ánimo de comentario.

Otavio (sic) confiesa a Sidonio padre de Elisa, cuyas cualidades no conoce por encontrarse en el exilio, la castidad de su hija:

SIDONIO: Luego ¿esta Elisa no es mujer de amores?

OTAVIO: ¿Cómo de amores? Es la honra misma, es un ángel del cielo; y no es milagro que sea honrada, porque tiene ejemplo en la matrona casta de su madre... (El piadoso veneciano, de 1599-1608, Acto III ${ }^{92}$ ).

87. Comedias, XIV, p. 916-917.

88. En el prólogo a Alvar (1984: 8).

89. Pero el tópico es anterior a ese movimiento. Así, Guido Guinizzelli, precursor de tal escuela, dirá a Dios, hablando de su dama: "Tenne d'angel sembianza / che foie del Tuo regno» (estr. VI, en Alvar 1984: 20; vid. la nota de este editor: p. 21, n. 21).

90. Vid. soneto IV de Fray Luis de León: «... ¡Oh figura / angelical!...» (vv. 7-8: cf. ed. de Ramajo, p. 163).

91. Vid., rima XIX de Bécquer, con incrustaciones románticas: «Cuando sobre el pecho inclinas / la melancólica frente, / una azucena tronchada / me pareces. / Porque, al darte la pureza / de que es símbolo celeste, / como a ella te hizo Dios / de oro y nieve».

92. Comedias, $X V$, p. 563. 
En Los Porceles de Murcia (1604-1608), don Vasco se ha enamorado de dońa Ana, hermana de un enemigo mortal, don Luis. Y de ella dice:

Es un ángel; no ha nacido

en Toledo más belleza,

más virtud, ni más nobleza (Acto $\mathrm{III}^{93}$ ).

Lucindo contempla a Fenisa, y se queda prendado:

Un ángel me ha parecido (La discreta enamorada, de 1604-1608, Jornada $\left.\mathrm{I}^{94}\right)$.

En Angélica en el Catay (1599-1603), el nombre de la protagonista permite jugar con el tema. Dirá Reinaldos:

Angélica no es del suelo,

que es su nombre celestial (acto I) ${ }^{95}$.

Clavela se casará con Feliciano, pese a la oposición de su padre. Es una donna angelicata. Así la ve Liberio, que aspira a su mano sin éxito. Ante la sugerencia de su criado de que se enamore de otra mujer, exclama:

¿Cómo puedo

bajar de un ángel único

a una mujer humana (La viuda, casada y doncella, de 1597-1598, acto I $)^{96}$.

Y Celio, criado de Feliciano, dirá de su ama:

... es un ángel en el suelo, y que la ha criado el cielo para un ejemplo de fe (La viuda, casada y doncella, de 1597-1598, acto II $)^{97}$.

En Peribáñez y el Comendador de Ocaña (1613) se califica de ángel tres veces a Casilda, la labradora de la que el noble queda prendado: vv. 323 (calificativo dado por el Comendador), 1672 y 2699 (calificativo dado por su propio marido ${ }^{98}$.

Albanio, al ver a su amada Ismenia queda paralizado. Parece haber eco de Dante ${ }^{99}$ :

93. Comedias, $X V$, p. 657.

94. Comedias, $X V$, p. 883. El tópico se repetirá insistentemente: cf. El leal criado, de 1594: Serafina, en boca de su enamorado, "Es extremada, / es angélica criatura» (acto I, Comedias, I, p. 451). En este caso, el nombre de la protagonista se acomoda bien al calificativo. Todavía dirá el criado Uberto «...Serafina, aquel ángel» (p. 500).

95. Comedias, $X$, p. 681.

96. Comedias, V, p. 744.

97. Comedias, V, p. 767.

98. Vid. Peribáñez y el Comendador de Ocaña, p. 24, 89 y 134, respectivamente.

99. Nos referimos en concreto al famoso soneto que comienza «Tanto gentile e tanto honesta pare / la donna mia...» (Vita nuova, cap. XXVI). 
...y no sé cómo en ver la prenda mía se cubre de un helado paroxismo el alma toda, que ya tiembla y muda. Yo hablo, y no soy yo, que yo no tengo instrumento, señora, que voz forme. Ymagínoos mujer y a hablaros vengo para que de mis males os informe; mas véoos ángel, y la voz detengo, que es la humana a la angélica disforme, y fuera bien, pues hay cielo en el suelo, que diera el cielo al suelo voz del cielo (Los amores de Albanio y Ismenia, de 1590-1595, Jornada I) ${ }^{100}$.

Importante es el tratamiento del tópico en Quien más no puede (1616). El rey Ordońo de León, prendado de Blanca, navarra, hermana del conde don Enrique, ve su hermosura corporal fundida en la del alma. La impronta neoplatónica es clara:

... en ella el cuerpo alma parece, pues si se viera el alma, no pudiera tener más hermosura, y en los cuerpos que son tan cristalinos, la hermosura del alma resplandece, como vemos una luz en un vidrio (acto II, 1035-1039) ${ }^{101}$.

La importancia de la virtud en la mujer alcanza su culminación en San Isidro Labrador (¿1604-1606?). El futuro santo elegirá mujer guiado exclusivamente por la virtud que tiene la novia, la futura Santa María de la Cabeza, verdadera donna angelicata ${ }^{102}$. Dice Isidro:

La novia tiene virtud, que es el dote verdadero para la paz y quietud (San Isidro Labrador, acto I ${ }^{103}$ ).

A veces Lope refleja la concepción que $\mathrm{M}^{a}$. Rosa Lida denominaría: «la dama como obra maestra de Dios» ${ }^{104}$. Así, Nemoroso pretende, en vano, describir a Jacinta:

\author{
Grosero pintor parezco, \\ que siendo el original \\ del artífice del cielo, \\ ningún pintor en el suelo
}

100. Comedias, III, p. 575.

101. Quien más no puede, p. 120.

102. Su mujer sirve a Isidro para elevarse hasta la belleza del Criador, en una escala claramente neoplatónica: «en su rostro alabo a Dios. / Si tiene tanta hermosura / una mujer en el suelo, / ¿qué será un ángel del cielo? / Y si la hermosa figura / de un ángel es de tal modo, / ¿cuál será el Criador, que, en fin, / es el principio y el fin, / sin principio y fin de todo?» (San Isidro Labrador, de ¿1604-1606?, acto I, Comedias, XIV, p. 889).

103. Comedias, XIV, p. 884.

104. Cf. Lida de Malkiel (1977). 
puede retratarle igual;

del mismo cielo te informa,

no de mi flaca miseria;

porque a tan alta materia

sólo Dios pudo dar forma... (Belardo el furioso, de 1586-1595, Jornada III $\left.^{105}\right)$.

La misma concepción expresará el príncipe Doristán en presencia de la infanta Lavinia:

¡Oh, Reina, cuya grandeza

de Dios testimonio es! (La infanta desesperada, de 1588-1595, Jornada I) ${ }^{106}$.

Interesante es el caso del personaje Ursón, cuyo nombre alude a haber sido amamantado por una osa. Pese a su ferocidad ha descubierto la belleza de la mujer y su origen divino ${ }^{107}$ :

Pienso que son [las mujeres] el traslado

de la hermosura que tiene [Dios] (Jornada II).

Por ello, se dirigirá así a una villana:

¡Oh semejanza de Dios! (Jornada II).

E insistirá con más claridad:

Por ti conozco que quien

te hizo ese rostro hermoso

es Dios todopoderoso... (Jornada II ${ }^{108}$.

105. Comedias, II, p. 533.

106. Comedias, III, p. 121.

107. A Lope le interesa la sabiduría de los indoctos, que trata en comedias de santos carentes de conocimientos teológicos, como en El rústico del cielo (1605). La impronta evangélica en estos casos es clara. Vid. la exaltación de los niños en Mateo, 18, 1-4; vid. la sabiduría que Dios confiere a los humildes y aparta de los soberbios: Mateo, 11, 25. La sabiduría del indocto se convierte en lugar común de la ascética cristiana: véase este pasaje del famoso libro De la imitación de Cristo, atribuido a Tomás de Kempis (s. XV), lib. I, cap. II: «Verdaderamente, mejor es el rústico humilde que sirve a Dios, que el soberbio filósofo que, olvidándose de sí mismo, contempla el curso de los astros» (citamos por la muy célebre trad. del. P. Nieremberg, p. 11).

108. Ursón y Valentín, hijos del rey de Francia, de 1580-1595, en Comedias, III, p. 221, 222 y 223, respectivamente. La calificación de ángel a la mujer llega a lexicalizarse. Valerio exclamará ante la presencia de Erifila: «¿Era mujer lo que vi / o era angel del cielo?» (Los locos de Valencia, acto I, 567-568, p. 151). Pero, en realidad, Erifila no es un ángel, es una apasionada mujer que huye de casa con quien cree que es su amor. Con todo, en la exclamación de Valerio acaso exista un calco de textos clásicos, en los que el hombre duda de si se encuentra ante una mujer o ante

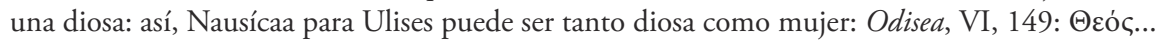
[o] Bрoтóc... Cf. Ramajo (2008: 163). 


\title{
III.2 Mujer: labradora
}

El gusto por la belleza natural viene de lejos. Ovidio dedicó todo el poema décimo cuarto del libro I de Amores a reprochar a su amada el que se hubiera cuidado en exceso los cabellos hasta estropeárselos: "Dicebam "medicare tuos desiste capillos"» (v. 1). Propercio compuso el poema segundo de su libro I de las Elegías para convencer a Cintia de que la belleza natural vale más que la conseguida con afeites. El poeta preguntará: "Quid iunat ornato procedere, uita, capillo...?» (v. 1: «¿De qué sirve, vida mía, presentarse con cabellos adornados...?»). Y es que «nudus Amor formae non amat artificem» (v. 7: "Amor desnudo no se complace de la belleza artificial").

Fray Luis, en La perfecta casada repudiará la belleza conseguida con afeites. Al tema dedicará todo el capítulo XI, acumulando, para el propósito, textos cristianos y paganos ${ }^{109}$.

En esa línea, Lope anota con frecuencia el caso del noble prendado de una o unas labradoras ${ }^{110}$. Bien conocidos son los ejemplos de Fuente Ovejuna (¿16121614?) o Peribánez y el Comendador de Ocaña (1613), tan cercanos en tema y cronología ${ }^{111}$. Las campesinas aúnan belleza con castidad. Así lo comprueba el vicioso noble don Tello. Ambas dimensiones figuran en Elvira, villana a la que forzará:

\author{
Hay algunas labradoras \\ que, sin afeites ni galas, \\ suelen llevarse los ojos, \\ y a vuelta dellos el alma; \\ pero son tan desdeñosas \\ que sus melindres me cansan (El mejor alcalde, el rey, de 1620-1623, \\ acto I, 515-520) $)^{112}$.
}

La apología del campo que Virgilio cantó en las Bucólicas y en las Geórgicas ${ }^{13}$ tendrá inmenso eco en las literaturas posteriores. Lope no será insensible a la tradición en buena parte creada por el mantuano ${ }^{114}$. También el Beatus ille

109. La numeración del capítulo responde al orden de San José Lera (1992: 138).

110. Obviamente, aquí entra en juego otro tema: el del honor. ¿Tienen honor los villanos? Fuente Ovejuna viene a responder afirmativamente a la pregunta que el Comendador dirige a los campesinos: «¿Vosotros honor tenéis?» (acto II, 989, p. 91). Y los nobles han de respetar una conducta adecuada para no perder la honra, que, como diría Calderón, es "patrimonio del alma», pues "No le hace al hombre honrado / el cargo, sino el ser hombre» (Lope de Vega, El hijo Venturoso, de 1598-1605, Jornada III, Comedias, III, p. 78).

111. Vid. Larson (1977).

112. El mejor alcalde, el rey, p. 81. La belleza sin afeites es objeto de alabanza entre los elegíacos latinos. Así, Ovidio reprocha a la amada por haber maltratado los cabellos con tintes. Ahora paga las consecuencias. Bien se lo había advertido: "Dicebam "medicare tuos desiste capillos" (Amores, I, xiv, 1).

113. Cf. Herreros Tabernero (2005).

114. Véase El ejemplo de casadas y prueba de la paciencia, de 1599-¿1603?. Está inspirada en Decamerón, III, 3. Pero la huella virgiliana es evidente. Laurencia, hermosa pastora, elegida como esposa por el conde Enrico de Moncada, vive en su marco natural antes de alcanzar tal 
horaciano (vid. vv. 39-48) le inspira el cuadro del hogar feliz, con la casada amorosa, que cuida al esposo al regresar de los trabajos ${ }^{115}$. Así dirá Casilda:

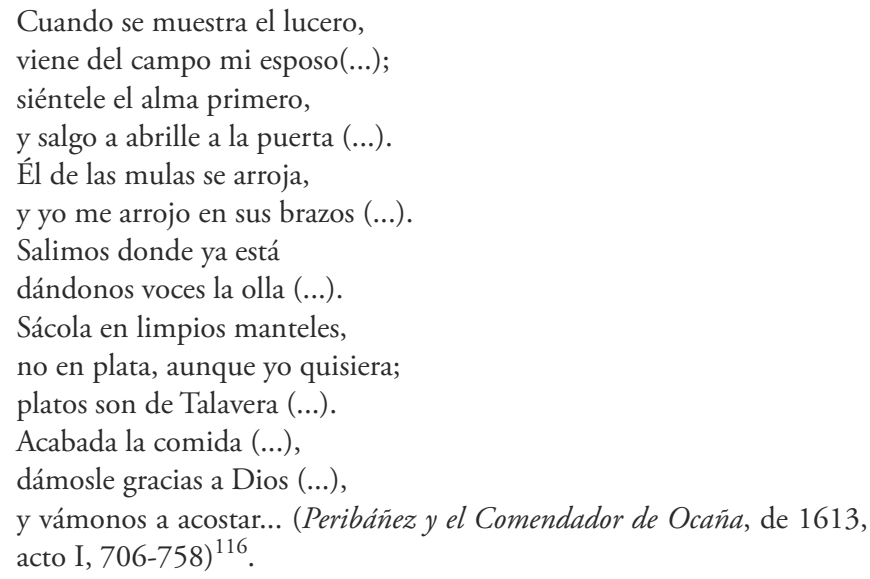

Defensa de la virtud y de la religiosidad frente a la pasión desatada de la falsa nobleza de los nobles. Y es que «... la virtud ha de ser / la verdadera riqueza» ( $L a$ noche toledana, de 1605 , acto $\mathrm{I}^{117}$ ).

Lope, el amador, convirtió en literatura, en teatro, una pasión que describió una y otra vez, al acecho de sus paradojas:

\author{
¡Dulce fuego, limpio ardor, \\ luz que ardiendo no se acaba; \\ divina conformidad, \\ regalo de los sentidos, \\ cuerpos con un alma unidos, \\ indivisible amistad...! (Angélica en el Catay, de 1599-1603, acto II) ${ }^{118}$.
}

dignidad. Allí los pastores debaten sobre cuestiones amorosas y buscan un juez, que será la propia Laurencia. Se establecen regalos para los triunfadores. A veces se cultiva la técnica de la écfrasis: "Yo / un vaso de enebro en quien / Venus y un fauno se ven...» (es reelaboración de Bucólicas, III, 35-48: El ejemplo de casadas y prueba de la paciencia, acto I, Comedias, XV, p. 216).

115. Vid. las certeras palabras de Menéndez Pidal: «Sorprende la serie de variantes con que trató tantas veces el tema horaciano del Beatus ille...» (en Treinta canciones, p. X). Para el Beatus ille, cf. Agrait (1971).

116. Peribánez y el Comendador de Ocaña, p. 44-46.

117. Comedias, XIII, p. 314.

118. Comedias, $X$, p. 727-728. Lope es dado a intentar definir el amor, en una tradición que acaso remonte a la poesía cancioneril. Vid. otros textos: «un monstruo es amor, con alas, /de nacimiento sin vista; / y porque es fuego en su centro, / a la salamandra imita. / Es una Etiopía al hielo, / y fuego ardiente en las Indias, / que como alarbe desnudo / arco embraza, flechas tira. / Quiere donde le aborrecen, / Huye de donde le obligan; / fáciles cosas desprecia / porque imposibles conquista..." (Las mocedades de Bernardo del Carpio, Jornada I, Obras, XVII, p. 10); "¿Amor? ¡Locura, furor! (...) / Es una dulce locura, / por quien la mayor cordura / suelen los hombres trocar» (La dama boba, acto I, 812-816, p. 95). A veces, Lope se deja empapar de la huella neoplatónica. Vid. Fuente Ovejuna, acto I, 409-411, p. 63-64: «... ¿Qué es amor? / Es un 


\section{Comedias citadas}

- El alcaide de Madrid (1599).

- El Amor enamorado (1635).

- Los amores de Albanio y Ismenia (1590-1595).

- Angélica en el Catay (1599-1603).

- Belardo el furioso (1586-1595).

- La bella malmaridada o la cortesana (1596).

- Las burlas de amor (1587-1595).

- El caballero del milagro (1593).

- El caballero de Olmedo (¿1620-1625?).

- Casa con dos puertas, mala es de guardar (Pedro Calderón de la Barca).

- La dama boba (1613).

- La discreta enamorada (1604-1608).

- El dómine Lucas (1590-1595).

- El ejemplo de casadas y prueba de la paciencia (1599-¿1603?).

- Los embustes de Celauro (1596-1598).

- La fe rompida (1599-1603).

- Las ferias de Madrid (¿1585-1589?).

- Fuente Ovejuna (i1612-1614?).

- El gallardo catalán (1599-1603).

- El hidalgo Bencerraje (1599-1608).

- El hijo Venturoso (1598-1605).

- La infanta desesperada (1588-1595).

- Las justas de Tebas y reina de las Amazonas (a. 1596).

- El leal criado (1594).

- Los locos de Valencia (1590-1595).

- El maestro de danzar (1594).

- El mejor alcalde, el rey (1620-1623).

- El mesón de la corte (¿1588?-1595).

- Las mocedades de Bernardo del Carpio (1599-1608).

- El molino (a. 1596).

- La moza de cántaro (1625-1627).

- La noche de San Juan (1631).

- La noche toledana (1605).

- Las paces de los Reyes y judía de Toledo (1610-1612).

- El palacio confuso (1624: atribuida también a Mira de Amescua).

- Los palacios de Galiana (no posterior a 1602).

- La pastoral de Jacinto (1588-1598).

- Peribánez y el Comendador de Ocaña (1613).

- El piadoso veneciano (1599-1608).

- Las pobrezas de Reinaldos (1599).

- Los Porceles de Murcia (1604-1608).

- El postrer godo de España (¿1599-1600?).

- Los Prados de León (1604-1606?).

- El príncipe despeñado (1602).

- El príncipe inocente (1590).

- La prueba de los amigos (1604).

- La puente del mundo (Auto Sacramental: fecha incierta).

- Quien más no puede (1616).

deseo / de hermosura...» (vid. McGrady 1993: 64). 
- San Isidro Labrador (¿1604-1606?).

- Santiago el Verde (1615).

- El secretario de sí mismo (1604-1606).

- La serrana de la Vera (1595-1598).

- Servir a señor discreto (1610-1618).

- El sol parado (1596-1603).

- Ursón y Valentín, hijos del rey de Francia (1580-1595).

- El verdadero amante (¿1585-1589?).

- Vida y muerte de Santa Teresa de Jesús (1622).

- El villano en su rincón (1614-1615).

- La viuda, casada y doncella (1597-1598).

\section{Comedias leídAs, AUNQUE NO CITADAS ${ }^{119}$}

- Adonis y Venus (1597-1603).

- El amante agradecido (1602).

- Anzuelo de Fenisa, El (¿1604-1606?).

- El Argel fingido y renegado de amor (1599).

- Asalto de Mastrique, El (¿1600-1606?).

- El castigo sin venganza (1631).

- Los celos de Rodamonte (1588-1595).

- Los donaires de Matico (a. 1596).

- El duque de Viseo (ca. 1609).

- Los embustes de Fabia (a. 1596).

- Los españoles en Flandes (1597-1606).

- La fábula de Perseo o La bella Andrómeda (1613-1614).

- El favor agradecido (1593).

- Lo fingido verdadero (ca. 1608).

- El sol parado (1596-1603).

- El genovés liberal (1599-1608).

- El Grao de Valencia (1595).

- El halcón de Federico (1599-1605).

- Los hechos de Garcilaso (¿1579-1583?).

- El hombre de bien (1604-1606).

- La infanta desesperada (1588-1595).

- Juan de Dios y Antón Martín (1611-1612).

- El lacayo fingido (1599-1603).

- El marqués de las Navas (1624).

- Los mártires de Madrid (¿1602-1606?). Comedia atribuida.

- El mayordomo de la duquesa de Amalf (¿1604-1606?).

- La mocedad de Roldán (1599-1603).

- La moza de cántaro (1625-1627).

- Las mudanzas de fortuna (¿1604-1607?).

- El niño inocente de La Guardia (¿1604-1606?).

- La obediencia laureada y primer Carlos de Hungría (1597-1606).

- El perro del hortelano (1613).

119. Incluimos este inventario para que el lector tenga presente las comedias lopescas que hemos leído, en las cuales, salvo error nuestro, no hemos encontrado los tópicos enumerados en el presente trabajo. Salvo que figuren citadas individualmente en las "Referencias bibliográficas», se han leído por la edición de la Biblioteca Castro, o, raramente, por Obras de Lope de Vega... 
- El primer rey de Castilla (1598-1603).

- El principe melancólico (a. 1604).

- Los Ramírez de Arellano (1599-1608).

- El remedio en la desdicha (1616).

- El rústico del cielo (1605).

- Saber por no saber, y vida de San Julián de Alcalá de Henares (a. 1620). Comedia atribuida.

- San Diego de Alcalá (1613).

- La Santa Liga (¿1598-1603?).

- Santiago el Verde (1615).

- El santo negro Rosambuco (antes de 1607).

- El testigo contra sí(1605-1606).

- La traición bien acertada (antes de 1604).

- La vida de San Pedro Nolasco (1629).

\section{Referencias bibliográficas}

Acuña Hernando de, Varias poesías, Madrid, 1591. Ed. de Luis F. Díaz Larios, Madrid, Cátedra, 1982.

Agrait Gustavo, El «Beatus ille» en la poesía lírica del Siglo de Oro, Puerto Rico, 1971.

Alonso Dámaso: vid. Góngora.

Alvar (1984): véase El Dolce Stil Novo.

Arjona José Homero, "El disfraz varonil en Lope de Vega», Bulletin Hispanique, 39, 1937, p. 1-27.

Asclepiades de Samos, Asclepiades de Samos. Epigramas y fragmentos. Estudio introductorio, ed. y trad. de Luis Arturo Guichard, Peter Lang, Berna y otras ciudades, 2004.

Autos sacramentales del Siglo de Oro, ed. de Enrique Rull Fernández, Madrid, Ediciones Libertarias, 2003.

Calderón de la Barca Pedro, Obras selectas [El principe constante, Casa con dos puertas, mala es de guardar, La dama duende. Amar después de la muerte, La vida es sueño, El mágico prodigioso, El Alcalde de Zalamea], Prólogo de Andrés Amorós, Madrid, Austral, 2000.

Calero Secall Inés, y Durán López Ma . de los Ángeles, coords., Debilidad aparente, fortaleza en realidad. La mujer como modelo en la literatura griega antigua y su proyección en el mundo actual, Málaga, Universidad, 2002.

Cancionero tradicional, ed. de José María Alín (Clásicos Castalia, 190), Madrid, 1991.

Cañas Murillo Jesús, «Diez calas en el amor en el teatro del primer Lope de Vega: la configuración del tema en las comedias del destierro", en Pedraza (2003: 235250).

Carreño (1998): véase Vega, Lope de.

Cervantes Miguel de, Don Quijote de la Mancha, ed. de Francisco Rico y otros (Biblioteca Clásica, 50), Barcelona, Crítica, 1998, 2 vols.

Classen Joachim, «Das Studium der Reden Ciceros in Spanien im fünfzehnten und sechzehnten Jahrhundert», Faventia, 24, 2002, p. 55-103.

Dixon Victor, «La huella en Lope de la tradición clásica: ¿honda o superficial?», Anuario de Lope de Vega, 11, 2005, p. 81-96.

Egido Aurora, «La página y el lienzo: sobre las relaciones entre poesía y pintura» (1989), en Fronteras de la poesía en el Barroco, Barcelona, Crítica, 1990, p. 164-197. 
El Dolce Stil Novo. Ed. y trad. de Carlos Alvar. Prólogo de L. A. de Cuenca, Madrid, Visor, 1984.

Entrambasaguas Joaquín, «Una traducción latina de Lope de Vega [el De deorum imaginibus de Albracio -autor inglés del s. XII-, Basilea, 1549]», en Estudios sobre Lope de Vega, Madrid, C.S.I.C., 1947, t. II, p. 507-526.

Faure Roberto, Diccionario de nombres propios, Madrid, Espasa Calpe, 2007.

Ferrer Valls Teresa, «Damas enamoran damas», en Pedraza Jiménez (2003: 191-212).

Galmes de Fuentes Álvaro, El amor cortés en la lírica árabe y en la lírica provenzal, Madrid, Cátedra, 1996.

Garcilaso de la Vega, Obra poética y textos en prosa, ed. de Bienvenido Morros, Barcelona, Crítica, 1995.

Góngora Luis de, Góngora y el «Polifemo», ed. de D. Alonso, 5ª ed., Madrid, Gredos, 1967, 3 vols.

- Sonetos completos, ed. de Biruté Ciplijauskaité (Clásicos Castalia, 1), 3ª . ed., Madrid, Castalia, 1978.

Gónzalez-Barrera Julián, "Lope de Vega y los librotes de lugares comunes: su lectura particular de Ravisio Textor», Anuario de Lope de Vega, 13, 2007, p. 51-71.

Guichard: véase Asclepíades de Samos.

Guimont Anny y Pérez Magallón Jesús, «Matrimonio y cierre de la comedia en Lope», Anuario de Lope de Vega, 4, 1998, p. 139-164.

Herrera Fernando de, Poesía castellana original completa, ed. de Cristóbal Cuevas, Madrid, Cátedra, 1985.

Herreros Tabernero Elena, "Las Geórgicas como modelo genérico en la literatura española», Cuadernos de Filología Clásica. Estudios Latinos, 25, 2005, p. 5-35.

Jameson A. K., «Lope de Vega's Knowledge of Classical Litterature», Bulletin Hispanique, 38, 1936, p. 444-501.

Kempis Tomás de, Imitación de Cristo, trad. del. P. Juan Eusebio Nieremberg, Madrid, Saturnino Calleja, 1901.

Lara Garrido J., "Acotaciones complementarias al motivo de los mansos en Lope de Vega», Dicenda, 2, 1983, p. 111-120.

Larsen Kevin S., "Suelta mi manso, mayoral extraño: Pastores y ovejas en un ciclo poético de Lope de Vega», Dicenda. Cuadernos de Filología Hispánica, 17, 1999, p. 119-126.

Larson Donald R., The Honor Plays of Lope de Vega, Cambridge, Massachusetts, Harvard University, 1977.

Lázaro Carreter Fernando, «Lope, pastor robado», en su vol. Estilo barroco y personalidad creadora, Salamanca, Anaya, 1966, p. 173-200.

León Fray Luis de, La perfecta casada, ed. de Javier San José Lera (Colección Austral, 275), Madrid, Espasa-Calpe, 1992.

- Poesía, ed. de Antonio Ramajo Caño. Estudio prelim. de Alberto Blecua y Francisco Rico (Biblioteca Clásica), Barcelona, Centro para la Edición de los Clásicos Españoles, Círculo de Lectores, 2006.

Lida de Malkiel María Rosa, "La dama como obra maestra de Dios», en Estudios sobre la literatura española del siglo XV, Madrid, Porrúa, 1977, p. 179-290.

López Bueno: vid. Rioja, Francisco de.

López Poza Sagrario, «La difusión y recepción de la Antología Griega en el Siglo de Oro", en En torno al canon: aproximaciones y estrategias, ed. de Begońa López Bueno, Grupo PASO, Sevilla, Universidad, 2005, p. 15-67. 
McGrady (1993): véase Vega, Lope de.

Mena Juan de, Obras completas, ed. de Miguel Ángel Pérez Priego, Barcelona, Planeta, 1989.

Menéndez Pidal Ramón, Flor nueva de romances viejos (Colección Austral, 100), 18ª . ed., Madrid, Espasa-Calpe, 1969.

Morley S. Griswold, y Bruerton Courtney, Cronología de las comedias de Lope de Vega, Madrid, Gredos, 1968.

Murgatroyd P., «Amatory, hunting, fishing and fowling», Latomus, 43, 1984, p. 362368.

Ojea Fernández María Elena, «Imágenes de mujeres en la literatura del Siglo de Oro. Lope de Vega y La dama boba», Epos, 23, 2007, p. 81-92.

Pabón (1945): véase Salustio.

Padilla Pedro, Laberinto amoroso de los mejores romances (Zaragoza, 1638), ed. de J. M. Blecua, Valencia, Castalia, 1953.

Pedraza Jiménez Felipe B., y otros, eds., Amor y erotismo en el teatro de Lope de Vega: actas de las XXV Jornadas de teatro clásico de Almagro (9-11 de julio de 2002), Almagro, Universidad de Castilla-La Mancha, 2003.

Pedraza Jiménez: vid. Vega, Lope de.

Poemas de amor y muerte en la Antología Palatina. Libro V y selección del libro VII. Edición de Cristóbal Rodríguez Alonso y Marta González González, Akal/Clásica, Madrid, 1999.

Profeti Maria Grazia, "Plauto, Lope y el teatro áureo», Anuario de Lope de Vega, 12, 2006, p. 191-210.

Ramajo Caño Antonio, "Anotaciones clásicas y cristianas a un poema de Lope de Vega ('¿Qué tengo yo que mi amistad procuras?')», Epos, 9, 1993, p. 619-629.

— «El carácter proemial de la oda primera de fray Luis (y un excurso sobre la priamel en la poesía de los Siglos de Oro)», Romanische Forschungen, 106, 1994, p. 84-117.

— «Huellas clásicas en un poema de Lope de Vega ('En la muerte de Baltasar Elisio de Medinilla')", en Studia Aurea. Actas del III Congreso de la Asociación Internacional Siglo de Oro (Toulouse, 1993), Toulouse-Pamplona, 1996, vol. I, p. 449-456.

- "'... De mi dichoso mal la rica historia': itinerario amoroso en el cancionero herreriano (1582)», Criticón, 86, 2002, p. 5-19.

— "Modelos literarios y autoridades lingüísticas en los Siglos de Oro», Cuadernos para Investigación de la Literatura Hispánica, 28, 2003, p. 381-414.

- "Cerrásteme la puerta rigurosa': exclusus amator, un tópico clásico en las letras españolas», Revista de Literatura, 66, 2004, p. 321-348.

— «Munus Mariae: Garcilaso, Égloga III», Boletín de la Real Academia Española, 88, enero-junio de 2008, p. 133-193.

Ramajo Caño (2006): véase León Luis de.

Ramos Rafael, "De Heródoto a Lope: nota a El mejor alcalde, el rey", Anuario Lope de Vega, 1, 1995, p. 235-240.

Rennert Hugo A., y Castro Américo, Vida de Lope de Vega, Madrid, 1919.

Rico Francisco, El pequeño mundo del hombre. Varia fortuna de una idea en las letras españolas (1970), 2a . ed., reimpr., Madrid: Alianza, 1988.

Rioja Francisco de, Poesía, ed. de Begoña López Bueno, Madrid, Cátedra, 1984.

Rodríguez Alonso: véase Poemas de amor y muerte en la Antología Palatina.

Rojas Fernando de, Comedia o Tragicomedia de Calisto y Melibea, ed. de Peter E. Russell (Clásicos Castalia, 191), Madrid, Castalia, 1991. 
Román Bravo: véase Terencio.

Romano Martín Sandra, "Un ejemplo de la influencia de la Eneida de Virgilio en el Isidro de Lope de Vega», Analecta Malacitana, 30, 2007, p. 565-574.

Romojaro Rosa, Lope de Vega y el mito clásico, Málaga, Universidad, s. a.: ¿1991?

Salustio, Conjuración de Catilina, ed. de José Manuel Pabón (1945), reimpr. de la 2a . ed., Madrid, Ediciones Clásicas, 1991.

San José Lera: véase León, Fray Luis de.

Santolaria Berta Amelia, "Pervivencia de los clásicos en el teatro de Lope de Vega», Anuario de Lope de Vega, 9, 2003, p. 175-193.

Séneca, Dialoghi, a cura di Giovanni Viansino, 12 reimpr., Milán, Mondadori, 2000, vol. II.

Terencio, Comedias, ed. bilingüe de José Román Bravo, Madrid, Cátedra, 2001.

«Treinta canciones de Lope de Vega... con unas páginas inéditas de Ramón Menéndez Pidal y Juan Ramón Jiménez (1635-1935) ", en Residencia. Revista de la Residencia de Estudiantes. Número extraordinario en Homenaje a Lope. Madrid, 1635.

Vega Félix Lope, $-A$ Study and Critical Edition of Lope de Vega's "El Amor enamorado", ed. De John B. Wooldridge, Jr., Madrid, Porrúa, 1978.

- La bella malmaridada o la cortesana, ed. de Chr. Andrés (Clásicos madrileños, 24), Madrid, Castalia, 2001.

- El caballero de Olmedo, ed. de F. Rico, Madrid, Cátedra, 1991.

- El castigo sin venganza: vid. El perro del hortelano.

- Comedias, I. Los hechos de Garcilaso. El principe inocente. El caballero del milagro. El favor agradecido. Laura perseguida. El leal criado. El maestro de danzar. San Segundo. Las justas de Tebas. Los embustes de Fabia (Biblioteca Castro ${ }^{120}$ ), Madrid, Turner, 1993.

- Comedias, II: El mesón de la corte. El verdadero amante. Los donaires de Matico. El molino. Las ferias de Madrid. Belardo el furioso. Las burlas de amor. Los celos de Rodamonte. El ganso de oro. El hijo de Reduán (Biblioteca Castro), Madrid, Turner, 1993.

- Comedias, III. El hijo Venturoso. La infanta desesperada. Ursón y Valentín. El principe melancólico. La traición bien acertada. El Grao de Valencia. Los amores de Albanio y Ismenia. El dómine Lucas. La ingratitud vengada. Los locos de Valencia (Biblioteca Castro), Madrid, Turner, 1993.

- Comedias, V. La serrana de la Vera. El cerco de Santa Fe. Los comendadores de Córdoba. El Marqués de Mantua. El amor desatinado. La imperial de Otón. Los torneos de Aragón. El rey Bamba. La viuda, casada y doncella. El galán Castrucho (Biblioteca Castro), Madrid, Turner, 1993.

- Comedias, VI. El alcaide de Madrid. El Argel fingido. El blasón de los Chaves de Villalba. Las pobrezas de Reinaldos. El soldado amante. La pastoral de Jacinto. La hermosa Alfreda. El padrino desposado. Los Benavides. Los embustes de Celauro (Biblioteca Castro), Madrid, Turner, 1993.

- Comedias, VIII. El amante agradecido. El caballero de Illescas. Roma abrasada. La fuerza lastimosa. La tragedia del rey don Sebastián. La viuda valenciana. La campana de Aragón. La resistencia honrada. El esclavo de Roma. El nuevo mundo (Biblioteca Castro), Madrid, Turner, 1994.

120. Todos los volúmenes de esta colección han sido editados por Jesús Gómez y Paloma Cuenca. Los editores no numeran los versos, y ello nos obliga a nosotros a la misma omisión cuando citamos por sus textos. 
- Comedias, IX. El sol parado. El testimonio vengado. El honrado hermano. Adonis y Venus. Los bandos de Sena. El desposorio encubierto. La pobreza estimada. La reina Juana de Nápoles. Arauco domado. Las Batuecas del duque de Alba (Biblioteca Castro), Madrid. Turner, 1994

- Comedias, X. Los locos por el cielo. El mayorazgo dudoso. Los pleitos de Ingalaterra. El primer rey de Castilla. La quinta de Florencia. La Santa Liga. El amigo por fuerza. Angélica en el Catay. La divina vencedora. Los esclavos libres (Biblioteca Castro), Madrid, Turner, 1994.

- Comedias, XI. La fe rompida. El gallardo catalán. El lacayo fingido. La mocedad de Roldán. El negro del mejor amo. La ocasión perdida. El postrer godo de España. La prisión sin culpa. El tirano castigado. Los tres diamantes (Biblioteca Castro), Madrid, Turner, 1995.

--Comedias, XIII. La nueva victoria del marqués de Santa Cruz. La prueba de los amigos. El halcón de Federico. La noche toledana. El rústico del cielo. Los españoles en Flandes. La obediencia laureada y primer Carlos de Hungría. El mayordomo de la duquesa de Amalfi. Los guanches de Tenerife y conquista de Canaria. El hombre de bien (Biblioteca Castro), Madrid, Turner, 1997.

- Comedias, XIV. El secretario de si mismo. El testigo contra sí. El gran duque de Moscovia. El santo negro Rosambuco. El asalto de Mastrique. La boda entre dos maridos. Don Juan de Castro I. Las mudanzas de fortuna. Los Prados de León. San Isidro Labrador (Biblioteca Castro), Madrid, Turner, 1998.

- Comedias, XV. El niño inocente de La Guardia. Don Juan de Castro II. El ejemplo de casadas y prueba de la paciencia. El genovés liberal. El hidalgo Bencerraje. El piadoso veneciano. Los Porceles de Murcia. Los Ramírez de Arellano. El anzuelo de Fenisa. La discreta enamorada (Biblioteca Castro), Madrid, Turner, 1998.

- La dama boba, ed. de Diego Marín, Madrid, Cátedra, 1976.

- El Duque de Viseo, observaciones preliminares de Elizabeth Aubert Eason, Valencia, Albatros Ediciones, $1969^{121}$.

- Los embustes de Celauro, ed. de Joaquín de Entrambasaguas, Zaragoza, Ebro, 1942 (esta edición numera independientemente cada uno de los actos).

- La Fábula de Perseo o La bella Andrómeda, ed. de Michael D. McGaha, Kassel, Reichenberger, 1985.

- Lo fingido verdadero, ed. de Maria Teresa Cattaneo, Roma, Bulzoni, 1992.

- Fuente Ovejuna, ed. de D. McGrady (Biblioteca Clásica, 54), Barcelona, Crítica, 1993.

- Los locos de Valencia, ed. de Hélène Tropé (Clásicos Castalia, 275), Madrid, Castalia, 2003.

- Lope de Vega's El palacio confuso, ed. de Charles Henry Stevens, Nueva York, Instituto de las Españas, 1939.

- El mejor alcalde, el rey, ed. de Frank P. Casa y Berislav Primorac, Madrid, Cátedra, 1993.

- La moza de cántaro, ed. de José Ma. Díez Borque (Colección Austral, 105), 3a . ed., Madrid, 1990.

- La noche de San Juan, ed. de Anita K. Stoll, Kassel, Reichenberger, 1988.

-Obras de Lope de Vega, XI. Comedias de vidas de santos, II. Ed. de M. Menéndez Pelayo (Biblioteca de Autores Españoles, 186). Reimpr.: La vida de San Pedro Nolasco, San

121. Reproduce, según confiesa, la edición de F. C. Sainz de Robles (Madrid, 1960), con división en escenas, de acuerdo con Hartzenbusch. No numera los versos. 
Diego de Alcalá, El niño inocente de La Guardia, Los mártires de Madrid y tres obras más [Juan de Dios y Antón Martín, El saber por no saber, y vida de San Julián de Alcalá de Henares, El rústico del cielo], Madrid, Atlas, 1965.

- Obras de Lope de Vega XVII. Crónicas y leyendas dramáticas de España. Ed. de M. Menéndez Pelayo (Biblioteca de Autores españoles, 190). Reimpr.: Las mocedades de Bernardo del Carpio. El casamiento en la muerte. El conde Fernán González. El bastardo Mudarra. Los Benavides. El vaquero de Moraña, Madrid, Atlas, 1966.

- Obras de Lope de Vega. XXVIII. Crónicas y leyendas dramáticas de España y comedias novelescas. Ed. de M. Menéndez Pelayo (Biblioteca de Autores Españoles, 233). Reimpr.: El Marqués de las Navas. La nueva victoria del Marqués de Santa Cruz. El Brasil restituido. La nueva victoria de D. Gonzalo de Córdova. Diálogo militar. Los palacios de Galiana, Madrid, Atlas, 1970.

- Las paces de los Reyes y judia de Toledo, ed. de James A. Castañeda, Chapel Hill, The University of North Carolina, 1962.

- La pastoral de Jacinto, ed. de Paola Ambrosi, Kassel, Reichenberger, 1997.

- Peribáñez y el Comendador de Ocaña, ed. de D. McGrady (Biblioteca Clásica), Barcelona, Crítica, 1997.

- El perro del hortelano. El castigo sin venganza, ed. de A. David Kossof (Clásicos Castalia, 25), 4a . ed., Madrid, 1990.

- Poesías líricas, ed. de José F. Montesinos (Clásicos Castellanos, 68 y 75), Madrid, Espasa-Calpe, 1968, 2 vols.

- El Príncipe despeñado, ed. de Ma. Soledad de Ciria Matilla, Pamplona, Gobierno de Navarra, 1992.

- Quien más no puede, ed. de Laura Naldini. Con una nota bibliográfica di Maria Grazia Profeti. Kassel, Reichenberger, 2001.

- El remedio en la desdicha, ed. de F. Lopez Estrada y Ma . Teresa López García-Berdoy, Barcelona, PPU, 1991.

— Rimas, ed. de Felipe B. Pedraza, Ciudad Real, Universidad de Castilla-La Mancha, 1993.

- Rimas humanas y otros versos, ed. de Antonio Carreño (Biblioteca Clásica, 52), Barcelona, Crítica, 1998.

- Santiago el Verde, ed. de Ruth Annelise Oppenheimer, Madrid, Consejo Superior de Investigaciones Científicas, 1940.

- Servir a señor discreto, ed. de Frida Weber de Kurlat (Clásicos Castalia, 68), Madrid, 1975.

— Vida y muerte de Santa Teresa de Jesús, ed. de Elisa Aragone Terni, Firenze, Università, 1970.

— El villano en su rincón, ed. de Juan Ma. Marín, Madrid, Cátedra, 1987.

Viansino: véase Séneca.

Ynduráin Domingo, «Enamorarse de oídas», Serta Philologica F. Lázaro Carreter, Madrid, Cátedra, 1983, p. 589-603. 